Portland State University

PDXScholar

Fall 1-14-2013

\title{
Horizontal Workplace Aggression and Coworker Social Support Related to Work-Family Conflict and Turnover Intentions
}

Sarah Elizabeth Van Dyck

Portland State University

Follow this and additional works at: https://pdxscholar.library.pdx.edu/open_access_etds

Part of the Industrial and Organizational Psychology Commons, and the Social Psychology Commons Let us know how access to this document benefits you.

Recommended Citation

Van Dyck, Sarah Elizabeth, "Horizontal Workplace Aggression and Coworker Social Support Related to Work-Family Conflict and Turnover Intentions" (2013). Dissertations and Theses. Paper 652.

https://doi.org/10.15760/etd.652

This Thesis is brought to you for free and open access. It has been accepted for inclusion in Dissertations and Theses by an authorized administrator of PDXScholar. Please contact us if we can make this document more accessible: pdxscholar@pdx.edu. 
Horizontal Workplace Aggression and Coworker Social Support Related to Work-Family Conflict and Turnover Intentions

$$
\text { by }
$$

\title{
Sarah Elizabeth Van Dyck
}

A thesis submitted in partial fulfillment of the requirements for the degree of

\author{
Master of Science \\ in \\ Psychology
}

Thesis Committee:

Leslie B. Hammer, Chair

Charlotte Fritz

Lin-Qin Yang

Portland State University

2012 


\begin{abstract}
Horizontal workplace aggression is a workplace stressor that can have serious negative outcomes for employees and organizations. In the current study, hierarchical regression analyses were used to investigate the hypotheses that horizontal workplace aggression has a relationship with turnover intentions, work-to-family conflict and family-to-work conflict. Coworker social support was investigated as a potential moderator in these relationships. Surveys measuring these constructs were administered to a group of 156 direct-care workers (specifically, certified nursing assistants, or CNAs) in a long-term assisted living facility corporation in the Northwestern United States. Results indicated that horizontal workplace aggression had a significant and positive relationship with work-to-family conflict, family-to-work conflict, and turnover intentions, and that coworker social support significantly moderated the relationship between horizontal workplace aggression and work-to-family conflict, though not in the hypothesized direction. No other hypothesized moderations were significant. Potential explanations, practical implications and directions for future research are discussed.
\end{abstract}


TABLE OF CONTENTS

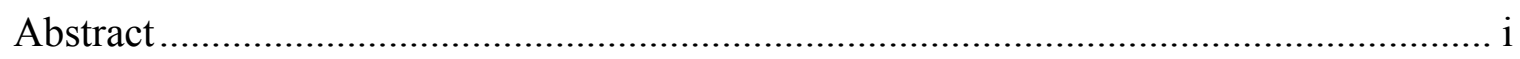

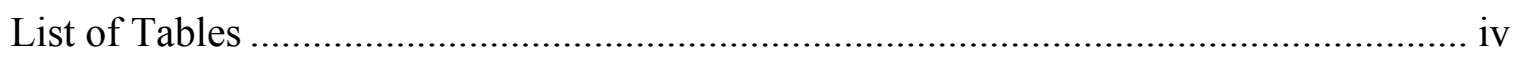

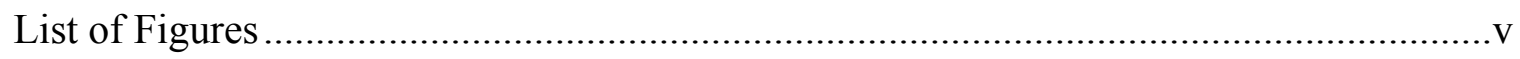

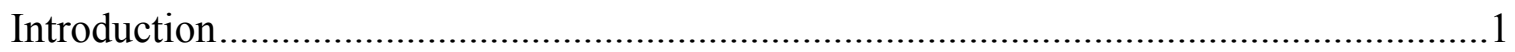

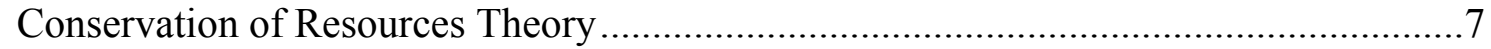

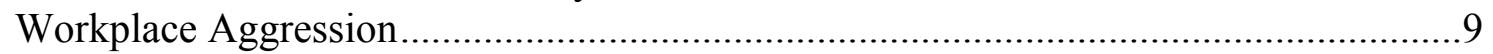

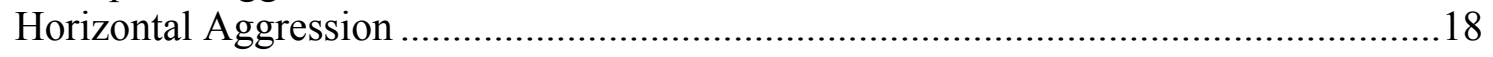

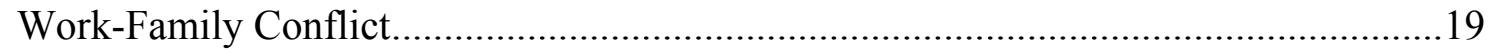

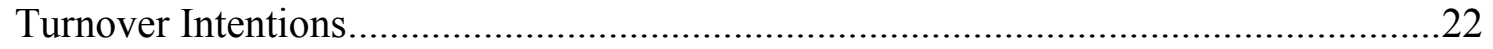

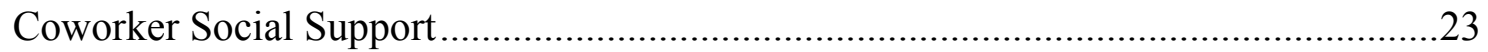

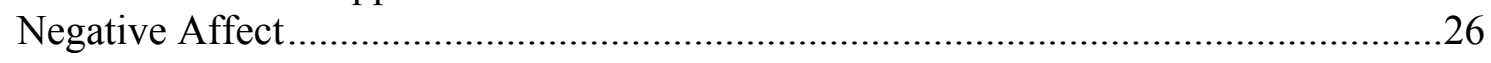

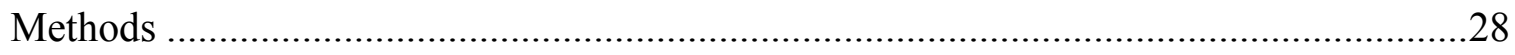

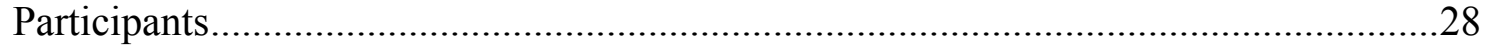

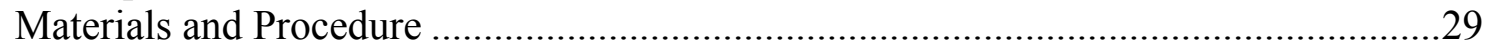

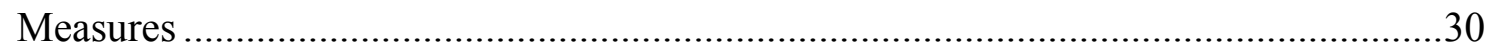

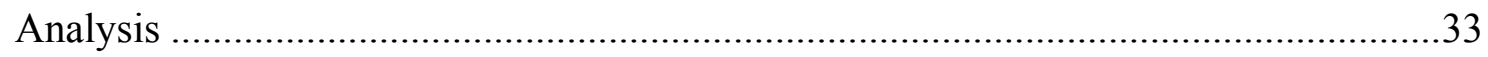

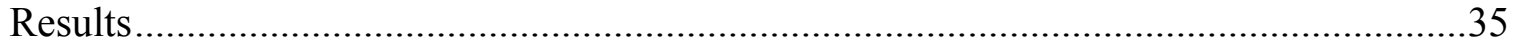

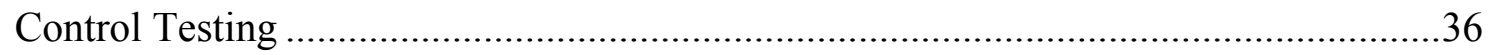

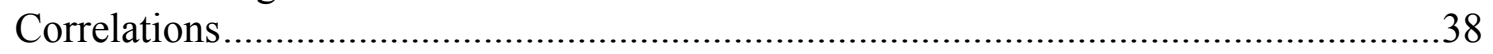

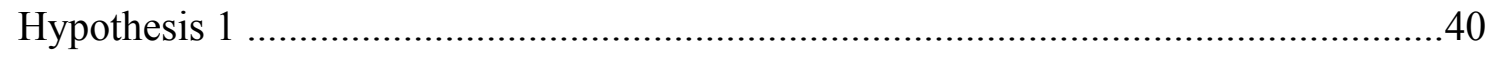

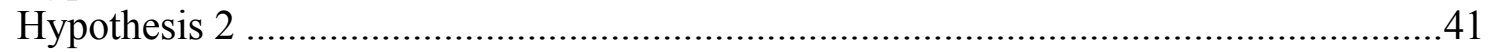

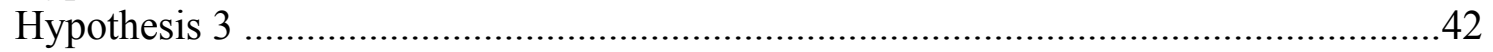

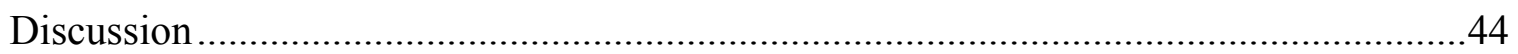

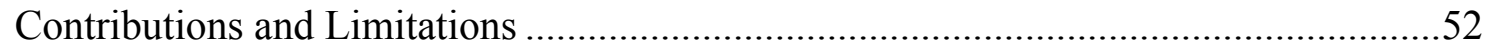

Future Research ..............................................................................................

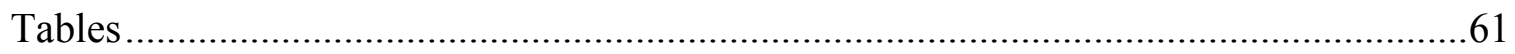

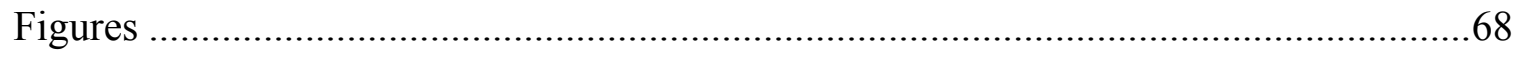

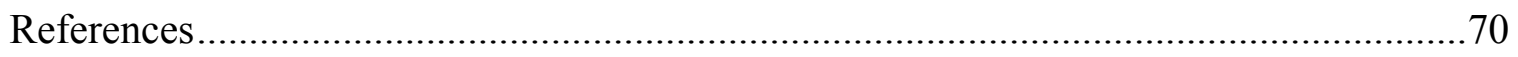

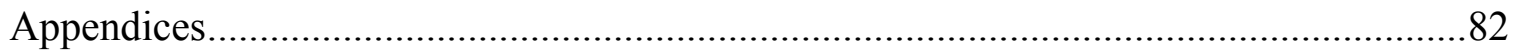

Appendix A: Negative Acts Questionnaire - Revised (NAQ-R) ..................................8

Appendix B: Work Family Conflict Questionnaire ......................................................83

Appendix C: Turnover Intentions Questionnaire.......................................................8 
Appendix D: Perceived Coworker Social Support Questionnaire .85 Appendix E: Positive and Negative Affect Schedule - Short Form (PANAS - SF)......86 Appendix F: Demographics Questionnaire. 
List of Tables

Table 1: Means, Standard Deviations, Intercorrelations and Internal Consistency

Estimates of Study Variables

Table 2: Standard Multiple Regression Results Predicting Work-to-Family Conflict from

Control Variable..... 62

Table 3: Standard Multiple Regression Results Predicting Family-to-Work Conflict from Control Variables .62

Table 4: Standard Multiple Regression Results Predicting Turnover Intentions from Control Variables .63

Table 5: Hierarchical Regression models tested .64

Table 6: Summary of Regression Analysis for Testing Hypothesis 1: The relationship between horizontal workplace aggression and work-to-family conflict, moderated by coworker social support.

Table 7: Summary of Regression Analysis for Testing Hypothesis 2: The relationship between horizontal workplace aggression and family-to-work conflict, moderated by coworker social support.

Table 8: Summary of Regression Analysis for Testing Hypothesis 3: The relationship between horizontal workplace aggression and turnover intentions, moderated by coworker social support. 67 


\section{List of Figures}

Figure 1: Hypothesized Model: Horizontal workplace aggression related to work-tofamily conflict, family-to-work conflict and turnover intentions..... .68

Figure 2: Significant interaction between horizontal workplace aggression and coworker

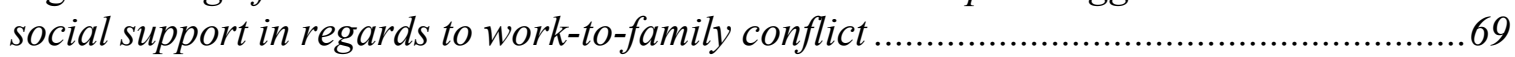




\section{Introduction}

More than $40 \%$ of American workers - 47 million people - are victims of workplace aggression, as reported in a recent national survey (Schat, Frone, \& Kelloway, 2006). The experience of workplace aggression is damaging to team cohesion, workplace goals, worker health and the health of their families (Duffy \& Sperry, 2007). Workplace aggression refers to the intent of an individual or individuals to physically or psychologically harm another person or other people at work (Schat \& Kelloway, 2005). While many American use the term "going postal" in a lighthearted manner in reference to reactions to excessive stress in a work environment, the episodes of workplace violence within the Unites States Postal Service (USPS) to which the colloquial phrase refers were anything but insignificant. Between 1983 and 2000, more than forty employees of USPS, members of the police force, and members of the public have been killed in over twenty episodes of extreme workplace violence (United States Postal Service Commission on a Safe and Secure Workplace [USPSC], 2000).

Surprisingly, the USPS workers are only a third as likely to be victims of workplace homicide as are members of some other national industries. The homicide rate per 100,000 workers within the USPS is .26 , while the retail industry and public administration have 2.1 and 1.66 respectively (USPSC, 2000). Though dramatic, these extreme events of workplace violence are relatively rare (Einarsen, 1999). More common are experiences of negative interactions in the more moderate range of the interpersonal conflict continuum. Workplace violence and workplace aggression fall under the larger 
umbrella of interpersonal conflict (McKenna, Smith, Poole \& Coverdale, 2002) but are conceptually distinct (Barling, Dupre, \& Kelloway, 2009). Workplace violence has been proposed to be a form of workplace aggression that includes acts intended to physically harm the victim, while workplace aggression encompasses a wide variety of negative interactions, ranging from rude or disparaging remarks, scapegoating, sexual harassment to physical violence (Schat \& Kelloway, 2005). Additionally, studies in this field have conceptualized workplace aggression as a type of antisocial employee behavior that violates workplace norms (Andersson \& Pearson, 1999). For the purposes of this study, I will conceptualize workplace aggression as a wide spectrum of negative interpersonal conflicts, ranging from incivility to physical violence, with a focus on the more common forms (non-physical). Although sources of workplace aggression can come from outside of the organization or within, this study follows the tradition of researchers focusing on aggression from within (O'Leary-Kelly, Griffin, \& Glew, 1996).

Aggression from within the workplace may be exacerbated by recent changes in the United States' workforce. Recent years have seen an increase in women and dual earner couples in the workplace, as well as an increase in racial and ethnic diversity in the workplace (Tetrick \& Quick, 2011). Harvey, Heames, Richey and Leonard (2006) examined the changing nature of the global workforce in relation to workplace aggression and propose that globalization, increased rapidity of business transactions, increased diversity, downsizing within the workforce and a reduction in levels of supervision due to downsizing are factors with probable links to increases in workplace aggression. Harvey 
and Keashly (2003) report that industry standards of long hours on the job and collocation increase the likelihood of experiencing aggression for two reasons: (1) long shifts increase the amount of time that the perpetrator and victim are in the same vicinity, increasing and intensifying contact, and (2) long hours may diminish personal resources and increase the likelihood of irritability, fatigue and frustration, leading to an increased likelihood of aggressive acts towards coworkers.

Furthermore, organizations in the United States employ around-the-clock staffing schedules in many sectors. Social services, such as police forces, hospitals, utility companies and public transportation must necessarily operate 24 hours a day. Organizations are responding to global forces in which consumers demand ever increasing speed and availability of services. A 24-hour economy has been driven by globalization, changes in consumption patterns, and by deregulation of the labor market (Strazdins, Korda, Lim, Broom, \& D’Souza, 2004). These changes may provide increased convenience and ability to meet market demands, but come at a cost. A wellresearched body of literature has shown that there can be serious consequences to the health and well-being of the individuals who work around the clock to operate these services and institutions (Perrucci et al., 2007).

This study focuses on an important population of shift-workers, direct-care workers in assisted living facilities. Direct-care workers in assisted living facilities staff the facility 24 hours a day. Those who are working outside of normal business hours are often disadvantaged, and are working low-paying, undesirable shifts (Presser, 2003a). 
Scholars have struggled to define shift work; it has been broadly conceptualized as any work that takes place outside of a standard Monday through Friday day shift (Costa, 2003). An umbrella term that encompasses most definitions is nonstandard work schedules, which incorporates part-time and shifts involving long hours (Barnett \& Hall, 2007). As the majority of new jobs in the United States take place outside of standard shifts, minorities, women, the undereducated and unskilled, and parents of young children are predisposed to working in disadvantaged circumstances. In addition to these challenges, Harris-Kojetin, Lipson, Fielding, Kiefer, and Stone (2004) identified the following issues with retention of direct-care workers in long-term care facilities:

... Inadequate training; poor public image of the LTC [long-term care] direct care workforce; low pay; insufficient benefits; inadequate job orientation and lack of mentoring; little or no opportunities for continuing education and development within the position; poor supervision; emotionally and physically hard work; workplace stress and burnout; personal life stressors, such as problems with housing, child care, and transportation; lack of respect from residents' families; and short staffing (p. 2).

For the direct-care worker population, there is little opportunity to take advantage of some of the more innovative scheduling practices available in other industries to help alleviate work-family conflict. This is mostly due to the nature of the work in the longterm assisted living industry. Each state has their own staffing requirement mandated by the Department of Human Services, and at a minimum must be adequate to meet the fire safety evacuation standards. For a direct-care staff member to leave his or her position without waiting for a replacement constitutes abandonment of the residents. Thus, flexible scheduling is very difficult to institute when around-the-clock care is need by 
residents, though some exceptions do exist. Strict scheduling guidelines are in place in many facilities, wherein an employee is placed on probation or terminated for missing part or all of a shift more than three times in ninety days. If a direct-care worker has a situation arise outside work that requires attention, he or she often trades shifts or barters with coworkers to cover his or her schedule to avoid the consequences of missing a shift. Additionally, the nature of the work is very interdependent; direct-care workers interact closely with coworkers, supervisors and residents throughout their entire shift, and often depend on coworkers and supervisors to safely accomplish patient care activities.

Due to the close and intertwined nature of the working relationships of direct-care workers, if an employee is experiencing workplace aggression, this may increase his or her experience of work-to-family conflict and family-to-work conflict. That employee may have a reduced capacity to draw upon resources at work to alleviate the work-family conflict that accompanies shift work and an inflexible schedule. Furthermore, based on previous research (Budd, Arvey \& Lawless, 1996), I hypothesized that experiencing high levels of workplace aggression may lead an employee to thoughts of leaving his or her organization. For these reasons, I chose to focus on work-to-family conflict, family-towork conflict, and turnover intentions as outcome variables in this study, with additional hypotheses regarding the moderating influence of coworker social support, as the addition of resources from other sources (such as more supportive coworkers) may ameliorate the workplace aggression stressor (Rousseau, Aube, \& Savoie, 2006). Hershcovis et al. (2007) found in their meta-analysis that interactional justice is a 
stronger predictor of workplace aggression that procedural justice. This discovery underpins the importance of relationships with supervisors, coworkers and subordinates.

Workplace aggression has frequently been linked to negative organizational and individual outcomes (Budd, et al., 1996; Lapierre, Spector \& Leck 2005; LeBlanc \& Kelloway, 2002; NNLIC, 1993; Schat \& Kelloway, 2000), but fewer studies have considered the impact that workplace aggression can have on the ability of the employee to balance work and family domains. While it is beyond the scope of this study to measure the effects of workplace aggression on the employees' family members, this study attempts to fill a gap in our knowledge regarding the relationship between workplace aggression and work-family conflict.

The purpose of this study is to strengthen the empirical and theoretical linkages between coworker aggression, work-family conflict and turnover intentions, as well as the moderating effects of coworker support. Haines, Marchand, and Harvey (2006) suggested that aggression experienced in the workplace holds a similar level of stress to the employee as other work-related stressors; Einarsen proposed that workplace aggression causes as much stress as all the others combined (1999). Haines at al. (2006) found that like these other stressors, workplace aggression can spillover into the family domain. Little empirical research has addressed the consequences of workplace aggression on the employee's experience of work-family conflict, with the notable exceptions of Tepper (2000), Haines et al. (2006) and Jansen, Kant, Kristensen, and Nijhuis (2003), which will be described in more detail shortly. As work-family conflict 
and workplace aggression have both shown to have detrimental effects on worker health and well-being and organizational outcomes (Bellavia \& Frone, 2005; Schat \& Kelloway, 2005), the relationship between these constructs is a fruitful area for research.

This study investigated a subconstruct of workplace aggression, horizontal aggression (aggression between coworkers) and its relationships with individual and organizational outcomes. This is an area that warrants additional investigation, as previous research has shown aggression from coworkers to uniquely predict negative effects on role ambiguity, job satisfaction and organizational commitment above the effects of supervisor aggression and organizational outsider aggression (Chaiburu \& Harrison, 2008). Additionally, I explored the possible moderating effect of coworker support on the relationship between horizontal aggression at work, work-family conflict and turnover, following previous research investigating intra-organizational social support as a buffer between a stressor (workplace aggression) and strain (Leather, Lawrence, Beale, Cox, \& Dickson, 1998). See Figure 1 for a model of these relationships.

This study investigated these relationships through the lens of the conservation of resources theory (COR; Hobfoll, 1989, 2001). The basic tenant of conservation of resources theory is that people strive to build and protect resources of value, and that stress occurs when these resources are threatened or diminished. Resources fall into four main categories: objects, conditions (tenure, good marriage, social support), personal characteristics (self-esteem), and energies (money, insurance) (Hobfoll \& Lilly, 1993). Resource loss is posited to be more salient than resource gain; in order to prevent loss 
individuals must invest other resources. The theory extends to suggest that individuals with more resources are buffered against loss and more capable of gaining additional resources, and those with fewer resources are more vulnerable to loss. In a cyclical manner, gains beget gains and losses beget losses. This can lead to a loss spiral for vulnerable individuals.

Theorists have conceptualized workplace aggression to be related to other workplace stressors through the process model of work stress (Schat \& Kelloway, 2005; Kahn \& Byosiere, 1990). The general model includes an aversive workplace stimulus, the individual's perception of the event, and their reaction. This model is closely linked to Lazarus and Folkman's (1984) transactional model of coping, (stress-appraisal-straincoping) in which the individual's perceptions of level and severity of threat from the environment influence the response of the individual to the threat. Hobfoll's model of conservation of resources $(1989,2001)$ expands upon traditional stress models (Lazarus \& Folkman, 1984, Selye, 1950) while retaining the important feature of the individual's perception of the environment and improving predictive capability.

Having introduced the conceptual basis of the current research, I now move to the main tasks of the project. I theorized that employees who experience aggression from some coworkers without experiencing support from other coworkers are drained of resources. Specifically, I expected to see this relationship manifest in increased rates of turnover intentions and work-family conflict for CNAs experiencing high levels of coworker aggression and low levels of coworker support. The current study expands on 
the existing literature by examining the full range of aggressive acts, from incivility through physical violence with a measurement instrument that allows aggressive acts to be split into work-related aggression, person-related aggression, and physically intimidating aggression, linking work-family conflict and workplace aggression between coworkers. Previous studies employed brief one- to three-item assessments of workplace aggression, did not specifically examine the role of horizontal aggression, and were part of larger data collections where pertinent individual characteristics, such as negative affectivity, were not obtained in the original data collection.

To illustrate the theoretical underpinnings of the current study, I expand the discussion of workplace aggression and horizontal aggression, addressing the definitional issues, prevalence and consequences to worker health, well-being and job-related outcomes. Second, I discuss work-family conflict and turnover intentions as possible outcomes of horizontal aggression. Third, I offer coworker support as a possible moderating factor in the relationships between the constructs above. Finally, I describe the current project, which investigated these concepts within a healthcare organization.

\section{Workplace Aggression}

Neuman and Baron (1998) propose that investigations into workplace aggression should be couched within the scope of the larger human aggression literature. Aggression has typically been classified along several dimensions: physical-verbal, active-passive, and direct-indirect, along with overt-covert (Buss, 1963). Consistent with that body of work, workplace aggression has been defined as "behavior by an individual or 
individuals within or outside an organization that is intended to physically or psychologically harm a worker or workers and occurs in a work-related context" (Schat \& Kelloway, 2005, p. 191). Workplace violence describes a subset of behaviors within workplace aggression intended to cause physical harm to the victim. Workplace aggression falls under the rubric of counterproductive workplace behaviors, and is thus closely related to various literatures that address hostile workplace behaviors (Keashly \& Jagatic, 2003).

A confusing fragmentation of these literatures has added to the lack of clarity surrounding defining workplace aggression (Hershcovis, 2011). Related concepts include workplace incivility (Andersson \& Pearson, 1999), workplace deviance (Robinson \& Bennett, 1995), workplace bullying (Namie \& Namie, 2000) and emotional abuse at work (Keashly, 1998). These constructs cross varying levels of ambiguity of intent by the perpetrator, duration, power imbalance, repetitiveness and escalation. To distinguish workplace aggression from bullying, mobbing, and victimization, Keashly (2001) emphasizes the latter as "interactions between organizational members that are characterized by repeated hostile verbal and nonverbal, often nonphysical behaviors directed at a person(s) such that the target's sense of him or herself as a competent worker and a person is negatively affected" (p.234). However, the behaviors described by the preceding related terms often overlap with behaviors ascribed to workplace aggression.

For the purposes of a thorough review of the literature on interpersonal conflict in 
the work context, I encompass what is known about mobbing, workplace deviance, bullying, incivility and other related concepts. For this research, I remain with the concept of workplace aggression as it is consistent with the larger human aggression literature (Neuman \& Baron, 1998) and encompasses a wide variety of negative or hostile workplace interactions. Along with other prominent researchers, leading aggression scholar Hershcovis (2011) has recently called for researchers to reconcile constructs within the field of study of mistreatment in the workplace. Hershcovis proposed that “workplace aggression" be employed as one all-encompassing construct as the field moves forward.

\section{Prevalence of Workplace Aggression}

Based on data from a nationally representative study of the 2,500 workers, Schat, Frone and Kelloway (2006) reported the prevalence of workplace aggression experienced in the United States. They reported the overall prevalence rates of workplace aggression, then parceled the frequency according to source: supervisor or manager, coworkers, and individuals outside the organization. The differentiation of source is important in this work; research suggests that the antecedents and consequences of workplace aggression differ by source (Schat et al., 2006, Greenberg \& Barling, 1999). For this review, I introduce the prevalence rates of the full spectrum of negative workplace interactions, but concentrate on the prevalence of nonviolent workplace aggression between coworkers.

Prevalence rates of fatal and nonfatal workplace violence have been more widely collected and studied than rates of workplace aggression (Schat et al., 2006). Preliminary 
data collected by the Bureau of Labor Statistics report that 521 workers in the United States died as a result of a violent attack on the job in 2009 , though rates of fatal workplace violence dropped approximately 50\% between 1994 and 2009, reflecting a downward trend (BLS, 2009). The most current nonfatal workplace violence statistics were not available at the time of preparation of this manuscript, but a 1993 survey conducted by Northwestern National Life Insurance company found that $15 \%$ of those surveyed has experienced some form of physical attack in the work context within the previous year (NNLIC, 1993). Between 1993 and 1999, data from the Bureau of Justice Statistics found that violent attacks in the workplace dropped by over $40 \%$, mirroring the decline in fatal workplace violence (Schat et al. 2006).

While some sources report that violence in the workplace is decreasing, others now call attention to the less dramatic, more covert forms of workplace aggression. Workplace violence has been called the "tip of the iceberg" of workplace aggression (Baron \& Neuman, 1998); this is reflected in data from a United States national survey (USPSC, 2000) in which 33\% percent of respondents reported experiencing verbal abuse at work. Greenberg and Barling (1999) surveyed 136 male employees of a Canadian university, and found that $82 \%, 74 \%$, and $76 \%$ admitted to aggressing against coworkers, subordinates and supervisors respectively. Bjorkqvist, Osterman, and Lagerspetz (1994) found in a study of 338 working adults that $30 \%$ of men and $55 \%$ of women reported experiencing workplace aggression. Furthermore, 32\% of respondents reported observing one or more episodes of a coworker being aggressed upon. The prevalence rates vary 
widely, due in part to differences in reporting periods and type of behavior (Schat et al., 2006). Together, these results emphasize the pervasive nature of workplace aggression.

\section{Predictors of Workplace Aggression}

Previous research has focused on the individual predictors of workplace aggression, as well as situational and organizational predictors. Individual difference predictors include Type A behavior (Baron, Neuman, \& Geddes, 1999), such that individuals with high Type A behavior patterns are more likely to behave aggressively than individuals with Type B tendencies. Alcohol use has been shown to predict higher levels of aggression towards coworkers (Greenberg \& Barling, 1999). Additionally, previous aggressive behavior as a young person has been shown to predict aggressive behavior as an adult (Greenberg \& Barling, 1999). In a nationally representative sample of the United States, gender has been shown to be a significant predictor of exposure to aggression at work, with men being more likely than women to report experiences of past workplace aggression. Age also has been found to be a significant predictor of experiences of workplace aggression, with danger of exposure rising until the age of 30 , and then falling in a linear pattern after 30 . Race and education level were not found to be significant predictors (Schatt, et al., 2006).

A large number of situational and organizational predictors have been suggested to affect workplace aggression. O'Leary-Kelly et al. (1996) suggest that factors of organizational culture can allow for situations to occur that condone workplace aggression. The factors they propose include modeling and perceived rewards for 
aggressive behavior, such that modeling of aggressive behavior and perceived rewards for aggressive behavior lead to increased levels of organizational aggressive culture. High levels of crowding or noise in the workplace can additionally create a more hospitable environment for workplace aggression. Leymann (1996) proposed that deficiencies in work design, deficiencies in leadership behavior, and a low organizational moral standard are organizational predictors of workplace aggression.

\section{Outcomes of Workplace Aggression}

Outcomes of workplace aggression have received considerable research attention. Based on his previous research, Barling (1996) proposed that the immediate outcomes of workplace aggression are negative mood and cognitive distractions and fear. Barling and McEwen (1992) found that chronic work stress is associated with negative mood, and that negative mood mediates the relationship between psychological stress and other outcomes. Chronic work stress has also been linked with cognitive distraction in balancing work demands and family demands (Barling \& McEwan, 1992). Barling proposes "workplace stressors produce cognitive arousal as individuals increase their vigilance in an attempt to cope with the situation" (1996, p. 41). Additionally, fear of aggression in either the victim or observers of workplace aggression is an important outcome of workplace aggression. Leblanc and Kelloway (2002) found that fear is a direct effect of workplace aggression; moreover, fear and perceived likelihood of future aggression were found to be highly correlated $(r=.70)$. Thus, the immediate effects of workplace aggression relate to anticipation of future aggressive acts. 
Long-term effects of workplace aggression include conditions that can seriously impair employee's health and well-being, such as anxiety and depression (LeBlanc \& Kelloway, 2002; NNLIC, 1993). Somatic symptoms include headaches, gastrointestinal disturbances, and insomnia (Schat \& Kelloway, 2000). Additionally, research has shown that workplace aggression can affect organizational functioning. Budd et al. (1996) found workplace aggression to be related to greater job stress and increased considerations of job change. Lapierre et al. (2005) found that individuals who perceived themselves to be victims of workplace aggression had significantly lower job satisfaction than those who did not perceive themselves to be targets for workplace aggression. $\mathrm{Ng}$ and Feldman (2008) suggest "acts of workplace aggression can cause bodily harm to employees, pose physical danger for customers, create public relations crises, and harm the business reputation of the firm as a whole." As such, the effects of workplace aggression can be dire.

Conservation of resources theory is valuable in examining workplace aggression in relation to resource loss and gain. The loss of resources in one or more domains, coupled with a decreased ability to replenish those resources corresponds with the spiral of loss described by Hobfoll (1989, 2000). Closely related, Demerouti, Bakker, and Butlers (2004) found that work pressure (such as experience of workplace aggression) and exhaustion were in a cyclical relationship corresponding with Hobfoll's loss spiral, wherein pressure from work can lead to a loss of resources, which then motivates the individual to attempt to gain resources in the work domain at the expense of the family 
domain. This leads to pressure and exhaustion, aggravating the loss spiral. Grandey and Cropanzano (1999) found that increased work stress could lead to increase family stress. Over time, stress reaction can result in decreased health, work-family stress and thoughts of leaving one's job. In short, conservation of resources theory posits that all individuals have some portion of valued resources that they are motivated to protect. Resources can fall into family domains (e.g. energy and time), as well as work domains (e.g., tenure, salary, self-esteem). COR offers a comprehensive theory for framing research involving work-family conflict (Grandey \& Cropanzano, 1999).

A few studies have begun to explore the effects of negative interactions at work on work-family conflict. Using random-digit dialing, Tepper (2000) recruited a total sample of 362 participants who filled out surveys at two time points, separated by six months. Tepper (2000) explored the outcomes of abusive supervision, and found that alongside other deleterious outcomes such as lower job and life satisfaction, abusive supervision was significantly and positively related work-to-family conflict and familyto-work conflict for employees who remained at their jobs as opposed leaving the organization. Tepper proposed that subordinates may be so anxious about his or her work situation that it may interfere with non-work time (work-to-family conflict), and that an abusive supervisor may exert pressure on a subordinate to devalue familial obligations in favor of work obligations such that any interjection of family duties are seen as family-towork conflict.

Jansen et al. (2003) employed two-year follow-up data from the Maastricht 
Cohort Study on "Fatigue at Work" ( $\mathrm{n}=12,095)$, a prospective study which investigated prolonged fatigue and the need for recovery, to study the antecedents and consequences of work-family conflict. The authors found conflict with coworkers or supervisors to be a risk factor for work-family conflict for men, but not for women. However, this study had only brief single-question measures of conflict with either coworkers or supervisors, and did not truly measure workplace aggression.

Drawing on crossover theory (Westman, 2001) in which stress experienced by an employee in the work domain crosses over to affect family life, Haines et al. (2006) discovered that workplace aggression (physical violence, intimidation, unwelcome remarks or gestures of a sexual nature) experienced by one or both partners accounts for significant psychological distress in his/her partner in a nationally representative survey of 2,904 working couples. Haines et al. (2006) employed hierarchical multilevel regression to investigate levels of psychological distress between members of dual-earner couples. Measures of workplace aggression were then added to the model, followed by the control variables, accounting for other common and individual stressors (marital strain, work-schedule irregularity, work hours, decision authority) and characteristics (age, sex). The final models showed that both individual and partner experiences of workplace aggression are related to higher levels of psychological stress after controlling for common and individual stressors. The authors noted, however, that they utilized data from a much larger collection (Quebec 1998 Health and Social Survey), and were thus unable to include pertinent measures (such as negative affectivity) in analyses. 
Furthermore, the authors recommended that future research include a more detailed measure of aggression, as their measure included only one item each regarding physical aggression, intimidation and sexual harassment. Though the current research linking workplace aggression and work-family conflict is limited, this avenue is promising.

\section{Horizontal Aggression.}

Quick (2000) defines horizontal aggression as aggression behavior that one employee commits against another in the workplace. Chaiburu and Harrison found in their 2008 meta-analysis of studies investigating the consequences of negative and positive coworker interactions that severity of negative coworker influences can act as an accelerant of negative social effects. Bowling, Beehr, Bennett and Watson (2010) in which the researchers discovered in a 13 month, two measurement point prospective study that victimization from co-workers was associated with victimization from supervisors. In concordance, Laymann (1996) posits that previous workplace aggression from co-workers stigmatizes the target, which leads to subsequent victimization from the supervisor. From this, it is clear that horizontal aggression is an important workplace stressor, and can lead to further victimization from other sources.

Prevalence of horizontal aggression. Prevalence reports vary by source. Hegney, Plank, and Parker (2003) found that 29\% of direct-care staff that had less than 5 years of tenure reported experiencing horizontal aggression. This corresponds with the USPSC (2000) survey, which found that $25 \%$ of respondents had been verbally abused by coworkers. LeBlanc and Kelloway (2002) reported between 25\% and 35\% of respondents 
had experienced nonphysical aggression from coworkers. Current estimates (Schat, Frone \& Kelloway, 2006) report that over 17 million workers (15\% of respondents) had experienced aggression from their coworkers. Importantly, outcomes of experience of workplace aggression differ by source. Whereas employees may be able to cope more effectively with single incidents of aggression from an organizational outsider, research has shown that reactions of victims of workplace aggression tend to be stronger and more negative when the perpetrator was a coworker (Hershcovis et al., 2007). Based on these points, I argue that horizontal aggression represents a large and significant portion of workplace aggression with unique attributes that qualify this subset for the focus of this study. I now move on to review the literature on work-family conflict and the theoretical ties to horizontal aggression.

\section{Work-Family Conflict}

The difficulty of balancing family demands with work demands has been studied extensively, and has been related to negative health outcomes such as burnout, psychological distress, and depression (Natemeyer, Boles, \& McMurrian, 1996). Workfamily conflict is defined as a type of interrole conflict, wherein the demands from one domain (work) interfere with the demands from another domain (home) to such a degree that participation in one precludes participation in the other (Edwards \& Rothbard, 2000; Natemeyer et al., 1996). Work-to-family (WTF) conflict and family-to-work (FTW) conflict have been conceptualized as distinct constructs with separate antecedents, which will be delineated below. The current study measured both directions of work-family 
conflict to allow investigation into what compromises employees might be making to satisfy role demands.

Byron investigated the antecedents of work-to-family conflict (WFC) and familyto-work conflict (FWC) in a 2005 meta-analysis. Byron found in the analysis that work domain antecedents of work-to-family conflict include job involvement, hours spent at work, work support, schedule flexibility, and job stress, such that job involvement, time spent at work and job stress increase work-to-family conflict, while work support and flexibility reduce work-to-family conflict. Non-work domain antecedents of family-towork include high family/non-work involvement, a large number of hours spent in nonwork, low family support, high family stress, high family conflict, larger numbers of children, age of youngest child, whether or not one's spouse is employed and marital status.

Allen, Herst, Bruck, and Sutton (2000) identified decreased job satisfaction, decreased organizational commitment, decreased job performance, decreased career satisfaction, and decreased career success as well as increased intentions to turnover and increased absenteeism as possible outcomes of FWC. They also founds that non-work related outcomes included decreased life satisfaction, decreased marital satisfaction, decreased family satisfaction, decreased family performance, and decreased leisure satisfaction. Perhaps most significant, the possible health effects resulting from chronic stress include general psychological strain, somatic/physical symptoms, depression, burnout, substance abuse, work-related stress, and family-related stress. 
Although anecdotal evidence abounds (O'Connell, Young, Brooks, Hutchings \& Lofthouse, 2000; Duffy \& Sperry, 2007) little empirical research has investigated the relationship between experiences of workplace aggression and work-family conflict, with a few notable exceptions (Tepper, 2000; Haines et al. 2006, Jansen, 2003). As discussed previously, Tepper (2000) drew on justice theory and found abusive supervision (a form of workplace aggression) to be a risk factor for work-to-family conflict and family-towork conflict for subordinates. Haines et al. (2006) discovered nationally representative survey of 2,904 working couples that workplace aggression experienced by one or both partners accounts for significant psychological distress in his/her partner.

While there is dearth of information describing the relationship between workplace aggression and work-family conflict, there is sufficient theoretical background on a variety of other workplace stressors to support hypotheses on the former. Laid upon groundwork of various stress theories, conservation of resources theory (COR) provides an appropriate framework for investigations into work-family conflict in conjunction with workplace aggression. Under the COR model, stress occurs when resources are lost or threatened. Resources such as favorable work conditions, personal characteristics (such as self-esteem) and energies may be lost or threatened by horizontal workplace aggression. Grandey and Cropanzano (2006) propose that as more conflict is experienced in one domain (work), fewer resources are available in the other domain (family). Additionally, to the extent which work environments emphasize the importance of workrelated obligations at the expense of family-related obligations, the employee may 
experience family-to-work conflict (Tepper, 2000). In high-dependency work environments in which employees are highly dependent upon one another to complete work-related tasks, negative reactions of coworkers to a fellow employee performing family responsibilities, such as leaving work to care for a sick child, may induce a reaction of a feeling of family-to-work conflict in the employee who leaves the workplace to care for his/her child (Tepper. 2000). Thus, I predicted that increased workplace aggression leads to an increase in both directions of work-family conflict.

H1a: Increased perceived horizontal aggression is related to increased work-tofamily conflict.

H2a: Increased horizontal workplace aggression is related to increased familyto-work conflict

\section{Turnover Intentions}

Annual turnover in nursing homes can be over $70 \%$ according to some studies, and has been associated with lower quality of patient care (Decker, Harris-Kojetin, \& Bercovitz, 2009). Voluntary employee turnover has been widely researched, and encompasses the employee's thoughts of quitting his/her current position, intention to search for another position, and intention to quit the position (Hom, Griffeth, \& Sellaro, 1984). Griffeth, Hom, and Gaertner showed in their 2000 meta-analysis that indicators of withdrawal were shown to predict turnover. These predictors include low job satisfaction, low organizational commitment, intention to search for alternative employment, comparison of alternatives, increased withdrawal cognitions, and quit intentions. To a 
lesser extent, high job stress, low work-group cohesion, low autonomy, low distributive justice and low promotional chances were also found to contribute to intention to quit (Griffeth et al, 2000).

Voluntary turnover can result in a host of negative organizational outcomes, including loss of productivity, institutional knowledge and leadership (Nyberg, 2010). Historically, global job satisfaction has been shown to be an important predictor of voluntary turnover (Mobley, 1977). Spector (1991) found that interpersonal conflict is an important job stressor, and is negatively related to job satisfaction. Budd et al. (1996) found that workplace aggression is related to decreased job satisfaction, greater job stress, and increased consideration of job change. Alternatively, Griffeth et al. (2000) found that workgroup cohesion has a significant modest negative relationship with turnover intentions. Few studies have measured the full spectrum of negative interactions with coworkers in relation to turnover intentions. To fill this gap in our knowledge, I proposed the following hypothesis:

H3a: Increased perceived horizontal aggression at work is related to increased turnover intentions.

\section{Coworker Social Support}

$\mathrm{Ng}$ and Sorensen (2008) defined coworker social support as "...the beliefs employees hold regarding the extent to which ... coworkers provide instrumental (workrelated) and emotional assistance." Social support has been shown to have significant effects on improvement of attitudes and health behaviors (Glanz, Rimer, \& Viswanath, 
2008), improvements in relationship quality with supervisors and residents (Noelker, Ejaz, Menne, \& Jones, 2006), buffer against work-family conflict (Jansen et al., 2003) and reduction in turnover (Findley \& Richardson, 2000). Peer social support in the workplace was even found to reduce the risk of mortality in a 20-year prospective study of healthy employees (Shirom, Toker, Alkaly, Jacobson, \& Balicer, 2011). Supervisor social support was not shown to have the same protective effects on employee health. Increased social support in the form of coworker social support may have important implications for the psychological health of workers by buffering against the negative effects of horizontal aggression (Rousseau et al., 2006). Additionally, Rousseau, Salek, Aube', and Morin (2009) found that coworker social support alleviated the effects of perceived distributional and procedural injustice, exemplified as perceived horizontal aggression.

In their 2008 meta-analysis of the research investigating the relationship between perceived supervisor support (PSS), perceived coworker support (PCS), and perceived organizational support (POS), Ng and Sorensen found that perceived supervisor support was generally more strongly related to positive work attitudes than was perceived coworker support. However, job-type (high-dependency vs. low-dependency) was found to be a significant moderator of the relationship between PCS and job satisfaction and PSS and job satisfaction. High-dependency work environments occur typically in customer service sectors (Ng \& Sorensen, 2008), which include many healthcare environments. In such environments, the job tasks of an individual are closely related to 
and intertwined with the job tasks of her/his coworkers.

Conservation of resources theory predicts that the addition of resources in one domain or role will decrease the resources expended into another role (Grandey \& Cropanzano, 1999; Hobfoll, 1989, 2001). I anticipated that stress experienced in the workplace as a result of horizontal aggression would diminish with the addition of greater coworker social support, in that a larger amount of resources would then be available for the family domain. Thus, coworker social support may reduce the amount of work-family conflict experienced by workers who also experienced negative interactions at work. I hypothesized the following relationships:

HIb: Coworker social support moderates the relationship between perceived horizontal aggression and work-to-family conflict such that work-to-family conflict is stronger at low levels of perceived coworker support.

H2b: Coworker social support moderates the relationship between perceived horizontal aggression and family-to-work conflict such that family-to-work conflict is stronger at low levels of coworker social support.

I also anticipated that employees who perceived the presence of coworker social support would report lower turnover intentions under circumstances of workplace aggression than employees who did not perceive coworker social support. Recent research has focused on the relational influence that perceived social support from a variety of sources can play upon the individual's decision to remain with the organization, conceptualizing social support as a factor of global job satisfaction $(\mathrm{Ng} \&$ 
Sorensen, 2008). Chaiburu and Harrison (2008) found in a meta-analysis synthesizing information from 72 studies containing information regarding both coworker and leader effects that social support from coworkers uniquely negatively and significantly associated with turnover intentions above the effect of leader social support. Based upon these results and the conservation of resources theory, I hypothesized the following relationship:

H3b: Coworker social support moderates the relationship between perceived horizontal aggression and turnover intentions such that turnover intentions are stronger at low levels of coworker social support.

\section{Negative Affect}

Though not specifically linked to any of the above-mentioned hypotheses, I have included negative affectivity as a control measure in this study. Negative affectivity refers to an overall disposition towards subjective distress (Watson, 1988), and has been associated with the larger study of human aggression. Research in the area of individual differences associated with experiences of workplace aggression have had mixed results, with some authors suggesting that there is a positive relationship between negative affectivity and workplace aggression (Andersson \& Pearson, 1999; Martinko \& Zellars, 1998), and others failing to find any evidence of this relationship (Douglas \& Martinko, 2001; Hershcovis et al., 2007). As noted by Hershcovis et al. in their 2007 meta-analysis, there are relatively few studies that investigate aggression between coworkers specifically, but those that do include measures of horizontal aggression may indicate 
higher levels of the experience of the interpersonal conflict phenomena. Thus, I feel it is important to include this ambiguous individual difference, to control for pre-existing feelings of sensitivity, irritability and general pessimism. 


\section{Methods}

In the preceding sections, I described the theoretical relationships between workplace aggression, work-family conflict, turnover intentions and perceived coworker support. Drawing upon conservation of resources theory, I posited that employees who experience a high level of workplace stress (in the form of horizontal workplace aggression) might have fewer resources to expend in the family domain, and thus experience a high level of work-family conflict and turnover intentions (Grandey and Cropanzano, 1996). In contrast, I reasoned that workers who have additional workplace resources (coworker social support) experience less conflict between the work domain and the family domain and less intentions to leave the organization. To explore these theories, I conducted the following study with direct-care staff in assisted living facilities.

\section{Participants}

The sample for this study was recruited from thirteen separate facilities of an assisted living corporation in the Northwestern United States. Initial recruitment of the assisted living corporation was made in March of 2010. After clarifying common goals with the C.O.O and head of the human resources department, I began to recruit facility administrators to participate in data collection with the assistance of human resources staff. After meeting by teleconference and hearing the research aims, thirteen facilities granted access to for recruitment. After passing through the required human subjects protection review, research activities began in June of 2011.

Participants were direct care workers (specifically, certified nursing assistants, or 
CNAs) employed within included employees from all three shifts from the 24-hour facilities. The shift hours are generally 7:00 A.M to 3:00 P.M., 3:00 P.M. to 11:00 P.M., and 11:00 P. M. to 7:00 A.M. Surveys were distributed on site during work hours of each of these shifts. A power analysis using $G^{*}$ power (Faul \& Erdfelder, 2007) indicated that a total sample of 119 people would be needed to detect medium effects $(\mathrm{d}=.15)$ with $95 \%$ power using a multiple regression model, with alpha at .05. Based upon this information, surveys were distributed to approximately 208 direct-care workers. We received 187 surveys back from participants, constituting an $89 \%$ response rate.

\section{Materials and Procedure}

I collected surveys between June 2011 and August 2011, traveling to each of the locations and administering the surveys in person. I worked with the human resources department manager and the director of nursing services at each facility to gain access to the direct care staff. The research project was verbally introduced to the nursing staff as a group at the beginning of each shift. I stressed the voluntary nature of participation, and emphasized that if an individual declined to participate in the study, this would not affect their position within the organization. I also took care to explain the ways in which I would keep their survey response information confidential from other staff members and from the organization. Staff who chose to participate were entered into a drawing for each facility for a $\$ 25$ gift certificate to Target.

With the help of the building administrators and human resources department representatives, I secured a location within each building in which to obtain informed 
consent and administer surveys without compromising the confidentiality of the participants. I asked the participating direct care workers to complete the survey after introducing the study and attaining informed consent to participate in the study. Participants were asked if they would like a copy of the informed consent document for their personal records, and copies were given to any who wished. Surveys took approximately 20 minutes to complete, and included items assessing demographics, negative trait affect, horizontal workplace aggression, coworker social support, turnover intentions and work-family conflict (see Appendices for survey instrument).

\section{Measures}

\section{Horizontal Workplace Aggression}

The construct of aggression between coworkers was operationalized using the Negative Acts Questionnaire-Revised (NAQ-R) by Einarsen, Notelaers, and Hoel (2009). This measure is primarily used to investigate employee's exposure to harassment at work. Participants respond to the twenty-two-item measure on a five-point Likert-type scale with $1=$ never, $2=$ occasionally, $3=$ monthly, $4=$ weekly, and $5=$ daily. Items are rated by frequency and include "Being ignored or facing a hostile reaction when you approach," "Someone withholding information which affects your performance," and "Threats of violence or physical abuse or actual abuse" (see Appendix A). I chose this scale as it has been internationally validated and has been widely used in studies of aggression, with the benefit of measuring a wide range of specific aggressive behaviors across the range of intensity. This scale may be used as one universal measure of 
workplace aggression, or split into three separate scales which each assess one of the following: work-related aggression, person-related aggression, and physically intimidating aggression. I performed a confirmatory factor analysis to compare the fit of a single-dimension model with all items loading onto the overall workplace aggression variable to a three-dimension model separating out the forms of aggression mentioned above. For this sample, there was no statistical difference between the single-dimension model and the three-dimension model. For the sake of parsimony, I proceeded to use the single-factor measure. Cronbach's alpha for the single factor measure for this sample = .95 .

\section{Work-Family Conflict}

Netemeyer et al. (1996) posit that work-to-family conflict and family-to-work conflict are empirically distinct constructs, and formed separate subscales to measure the extent to which work demands conflict with family demands and family demands conflict with work demands. Participants answered a 10-item survey on a seven-point Likert-type scale $(1$ = strongly disagree to 7 = strongly agree $)$ (see Appendix B). Items assess workto-family conflict in the first five of the questions ("The demands of my work interfere with my home life," "The amount of time my job takes up makes it difficult to fulfill my family responsibilities," "Things I want to do at home do not get done because of the demands my job puts on me) and family-to-work conflict in an additional five items ("The demands of my family or spouse/partner interfere with work-related activities," "I have to put off doing things at work because of the demands on my time at home"). 
Cronbach's alpha for work-to-family conflict for this sample $=.93$. Cronbach's alpha for family-to-work conflict for this sample $=.89$.

\section{Turnover Intentions}

Participants rated their intention to leave the organization using four items, each measured on a five-point scale $(1=$ strongly disagree to $5=$ strongly agree $)$. Items were developed for a longitudinal study investigating work and family conflict (Kelloway, Gottlieb, \& Barham, 1999) and include "I am thinking about leaving this organization," "I am planning on looking for a new job," "I intend to ask people about new opportunities," and "I don't plan to be in this organization much longer" (see Appendix C). Cronbach's alpha for this sample $=.95$.

\section{Coworker Social Support}

Perceptions of coworker social support were measured with a four-item section developed by Caplan, Cobb, French, Van Harrison, and Pinneau (1980). Ray and Miller (1994) added two additional items assessing coworker respect to the original scale (see Appendix D). Items included questions such as "How much does each of these people go out of their way to do things to make your work life easier for you?" Respondents were presented with a five-point Likert-type scale, where they circled their level of agreement with the statements regarding workplace support $(1=$ don't have any such person, $2=$ not at all, $3=$ a little, $4=$ somewhat, $5=$ very much). Cronbach's alpha for this sample $=.86$.

\section{Negative Affect}

The Positive and Negative Affect Schedule - Short Form (PANAS - SF) 
(Thompson, 2007) was used to measure negative affect in this study (see Appendix E). Five items measured the participant's trait affect on a five-point Likert-type scale $(1=$ never to $5=$ all of the time). Participants were asked to consider how they normally feel, then rate the frequency they recall feeling hostile or nervous, for example. Cronbach's alpha for this sample $=.79$.

\section{Demographics}

Demographic information assessed for potential control variables included age, gender, marital status, number of dependent children living at home, amount of eldercare provided, hours worked based on former work-family conflict research (Eby et al. 2005) (see Appendix E).

\section{Analysis}

Moderated multiple regression was employed to assess each outcome variable. Potential controls were pre-tested for inclusion in the final model to preserve power, and all continuous independent variables were centered. To limit family-wise error rates, only three regression models were examined. To evaluate Hypothesis 1, all applicable control variables were entered in the first step and regressed upon work-to-family conflict. In the second step, horizontal workplace aggression was entered as the independent variable. Coworker social support was entered as the moderator in the third step, and the interaction term "horizontal workplace aggression*coworker social support" created from the centered IV and moderator variables was entered in the fourth step. The following regression equation was estimated: 


$$
\mathrm{Y}=\mathrm{a}+\mathrm{bX}+\mathrm{cM}+\mathrm{dXM}
$$

To evaluate Hypotheses 2 and 3, the same method was employed to assess the relationship between perceived horizontal aggression and family-to-work conflict as moderated by coworker social support, as well as the relationship between horizontal workplace aggression and turnover intentions as moderated by coworker social support. 


\section{Results}

Missing data were deleted on a listwise basis. Mean scores were computed for each of the scales, and if a participant was missing a score for one of the scales included in a model, the rest of his or her information was counted as missing from the analysis. Though a total sample size of 183 participants was collected, after listwise deletion, the final sample size analyzed was 156 participants. Twenty deletions were due to missing a value for age. Of the other scales, no more than 2 cases per scale were deleted due to missing values. Descriptive statistics, histograms and scatterplots were examined for violations of assumptions of normality and homogeneity of variance, and to identify potential outliers within the data. Examination of the data revealed no cause for concern.

Of the final sample of 156 participants, 137 (87.8\%) were women and 17 (10.9\%) were men. While this is quite a discrepancy, the percentage of female to male respondents in this study corresponds with the findings of the Paraprofessional Healthcare Institute (PHI), who draw upon information from the national direct-care worker population (Polzer, 2012). PHI found that the national average of male direct-care workers was just $11 \%$. Ages of the participants ranged from 18 to 64 , with a mean age of $34.83(\mathrm{SD}=11.91)$. In regards to race and ethnicity, $126(87 \%)$ survey respondents identified their ethnicity as Caucasian, 16 (23\%) as Black or African American, 6 (3.8\%) as Asian, $2(1.3 \%)$ as American or Alaskan Native, $2(1.3 \%)$ as Native Hawaiian or Pacific Islander and $2(1.3 \%)$ respondents chose not to identify. As the reader may notice, the sum of the percentages chosen by participants does not add up to $100 \%$. Many of the 
study participants chose multiple races to reflect their identity. Of the 156 respondents, $22(14 \%)$ of participants selected Hispanic as their ethnicity. When asked about nationality, $138(88 \%)$ of respondents indicated that they were born in the United States. In terms of education, 9 (5.8\%) respondents had some high school education, 58 (37\%) respondents graduated from high school or obtained a GED, and an additional 85 (54\%) had some college education or an associate's degree. Only $3(1.9 \%)$ respondents had earned a bachelor's degree, and none had completed any graduate work.

When asked about relationship status, 67 (43\%) of respondents reported being married or partnered, and an additional 29 (19\%) reporting living with a significant other, while $33(22 \%)$ reported being divorced or separated, and $23(15 \%)$ reported having never been married. Of the 156 respondents, 84 (55\%) respondents reported having one or more dependents under the age of 18 living in their household, and 59 (38\%) respondents reported that they or their partner provided three or more hours of care per week for an adult family member.

In regards to work demographics, respondents worked on average 36.99 hours a week $(\mathrm{SD}=37.53)$, with a minimum of 8.0 hours worked per week on average, and a maximum of 75.0. The average length of time that respondents indicated having been employed in their current position was $4.23(\mathrm{SD}=5.69)$ with a minimum of one month in current position, and a maximum of 29 years in current position.

\section{Control Testing}

To preserve power in the final models, potential control variables were pre-tested 
for inclusion. See Tables 2 - 4 for a summary of results. Employee gender, employee age, relationship status, number of minor dependents living with the employee, whether or not the employee or his/her partner provided more than three hours a week of elder care, the average number of hours an employee worked per week, and employee negative state affect were included in data collection as potential control variables. Employee age, number of minor dependents, affect and average number of hours worked per week were left as continuous variables. Variable measuring relationship status and whether or not the employee or his/her partner provided more than three hours a week of elder care were dummy coded. Employee gender was originally measured as a dichotomous variable. I ran three standard multiple regressions, with work-to-family conflict, family-to-work conflict and turnover intentions as the three respective outcome variables.

For the regression with work-to-family conflict as the outcome variable, the standard multiple regression indicated that the combination of variables did significantly predict work-to-family conflict, $R^{2}=.17, F(7,135)=3.91, p<.01$. Results indicated that when controlling for employee gender, relationship status, number of minor dependents living with the employee, whether or not the employee or his/her partner provided more than three hours a week of elder care, and the average number of hours an employee worked per week, employee age $(\beta=-.18, t=-2.18, p<.05)$ and employee affect $(\beta=$ $.32, t=3.93, p<.001$ ) significantly predicted work-to-family conflict (see Table 2).

For the regression with family-to-work conflict as the outcome variable, the standard multiple regression indicated that the combination of variables significantly 
predicted family-to-work conflict, $R^{2}=.12, F(7,136)=2.63, p<.01$. Results indicated that when controlling for employee age, employee gender, relationship status, number of minor dependents living with the employee, whether or not the employee or his/her partner provided more than three hours a week of elder care, and the average number of hours an employee worked per week, only employee affect $(\beta=.33, t=3.90, p<.001)$ significantly predicted family-to-work conflict (see Table 3).

For the regression with turnover intentions as the outcome variable, the standard multiple regression indicated that the combination of variables significantly predicted turnover intentions, $R^{2}=.23, F(7,136)=5.80, p<.01$. Results indicated that when controlling for employee gender, relationship status, number of minor dependents living with the employee, whether or not the employee or his/her partner provided more than three hours a week of elder care, and the average number of hours an employee worked per week, employee age $(\beta=-.34, t=-4.32, p<.001)$ and employee affect $(\beta=.32, t=$ 4.03, $p<.001)$ significantly predicted turnover intentions. Thus, employee age and affect were included as controls in hypothesis testing (see Table 3). In summary, as a result of the three standard multiple regressions described above, only employee age and affect were shown to significantly predict any of the outcome variables of all potential control variables, and thus were the only two control variables included in the final models for hypothesis testing.

\section{Correlations}

Intercorrelations, scale reliabilities, means, and standard deviations for all 
variables included in analyses can be found in Table 1. Preliminary analyses indicated that horizontal workplace aggression had a significant negative and moderate association with coworker social support and positive affect. Additionally, coworker social support was significantly and positively associated with positive affect. As hypothesized in this study, horizontal workplace aggression has a significant and moderate relationship with work-to-family conflict, family-to-work conflict and turnover intentions, potentially providing partial support for hypotheses 1a, 2a, and 3a.

\section{Hypothesis Testing}

To investigate possible confounding facility-level mean differences among the 13 data collection sites, the intraclass correlations (ICC) were examined in preliminary analysis to determine whether there were significant differences in turnover intentions, work-to-family conflict or family-to-work conflict across facility, indicating the errors are correlated and the assumption of independence of errors is violated. This can lead to an inflation of Type I error rates (rejection of a true null hypothesis), though generally in larger samples than this study. Even ICC values of .01 can inflate Type I error rates (Barcikowski, 1981). The intraclass correlations for work-to-family conflict and turnover intentions were less than .01 , indicating small reason for concern regarding dependence of measures. The intraclass correlation for family-to-work conflict was .03, but a oneway ANOVA showed that there were no statistically significant differences in mean family-to-work conflict scores across facilities, $\mathrm{F}(12,143)=1.58, \mathrm{p}>.05$.

I thus proceeded to test my hypotheses with hierarchical moderated multiple 
regression. The predictors for the models estimated were employees' perceptions of horizontal workplace aggression, coworker social support and the interaction term created from the two. All predictor variables were grand-mean centered; this step prevents multicollinearity associated with the creation of interaction terms (Tabachnick \& Fidel, 2007). See Table 5 for a summary of each model.

Hypothesis 1 . I hypothesized that increased horizontal workplace aggression would be related to increased levels of work-to-family conflict (H1a), and that coworker social support would moderate the relationship, such that work-to-family conflict would be stronger at low levels of coworker social support (H1b). The first model evaluated my first set of hypotheses. Controlling for employee age and negative affect, I entered horizontal workplace aggression as the predictor in the model, with work-to-family conflict as the outcome variable. Results indicated that perceived horizontal aggression predicted work-to-family conflict, $(\beta=.22, t=2.52, p<.05)$, supporting H1a (see Table 6). I then added the moderator, coworker social support, and the interaction term, horizontal workplace aggression*coworker social support from the grand-mean centered IV (horizontal workplace aggression) and moderator (coworker social support). Controlling for employee age, negative affect, horizontal workplace aggression and coworker social support, results indicated the coworker social support moderated the relationship between horizontal workplace aggression and work-to-family conflict ( $\beta$ $=.22, t=2.73, p<.01)$. To explore the nature of this interaction, I graphed the values for one standard deviation above and below the mean of coworker social support and values 
for one standard deviation above and below the mean of horizontal workplace aggression (see Figure 2). The graphic representation of the interaction shows that the nature of the interaction is not as hypothesized. Work-to-family conflict appears to remain constant (though relatively elevated) for employees who report low coworker social support through times of both low and high horizontal workplace aggression (see Figure 2). Employees who reported higher levels of coworker social support indicated relatively lower levels of work-to-family conflict under conditions of horizontal workplace aggression, but work-to-family conflict became elevated under conditions of increased horizontal workplace aggression.

Hypothesis 2. The second model evaluated $\mathrm{H} 2 \mathrm{a}$, in which I hypothesized that higher levels of horizontal workplace aggression would be related to higher levels of family-to-work conflict and $\mathrm{H} 2 \mathrm{~b}$, in which I hypothesized that coworker social support would moderate the relationship between horizontal workplace aggression and family-towork conflict, such that family-to-work conflict would be stronger at low levels of coworker social support. Controlling for employee age and negative affect, I first entered horizontal workplace aggression as the predictor in the model, with family-to-work conflict as the outcome variable. Results indicated that perceived horizontal aggression predicted family-to-work conflict, $(\beta=.52, t=6.30, p<.001)$, supporting H2a (see Table 7). To test the moderator hypothesis, I created the interaction term 'horizontal workplace aggression * coworker social support' from the grand-mean centered IV (horizontal workplace aggression) and moderator (coworker social support). Controlling for 
employee age, negative affect, horizontal workplace aggression and coworker social support, the results showed a no significant interaction between perceived horizontal aggression and perceived coworker social support related to family-to-work conflict ( $\beta=$ $.11, t=1.57, p>.05)$.

Hypothesis 3. The third model evaluated H3a, in which I hypothesized that higher levels of horizontal workplace aggression would be related to higher levels of turnover intentions, and $\mathrm{H} 2 \mathrm{~b}$, in which I hypothesized that coworker social support would moderate the relationship between horizontal workplace aggression and turnover intentions, such that turnover intentions would be stronger at low levels of coworker social support. Controlling for employee age and negative affect, I first entered horizontal workplace aggression as the predictor in the model, with turnover intentions as the outcome variable. Results indicated that perceived horizontal aggression was related to turnover intentions, $(\beta=.26, t=3.08, p<.01)$, supporting H3a (see Table 8$)$. To test the moderator hypothesis, I created the interaction term 'horizontal workplace aggression* coworker social support' from the grand-mean centered IV (horizontal workplace aggression) and moderator (coworker social support). Controlling for employee age, negative affect, horizontal workplace aggression and coworker social support, the results showed a no significant interaction between perceived horizontal aggression and perceived coworker social support related to turnover intentions $(\beta=.09, t=1.23, p>$ $.05)$. 


\section{Summary of Results}

The only proposed control variables that were significantly related to work-tofamily conflict, family-to-work conflict or turnover intentions were employee age and negative affect. Horizontal workplace aggression was found to be significantly and positively related work-to-family conflict, family-to-work conflict and turnover intentions, as hypothesized ( $\mathrm{H} 1 \mathrm{a}, \mathrm{H} 2 \mathrm{a}$, and $\mathrm{H} 3 \mathrm{a})$. In terms of the hypothesized moderation relationships, only one of the proposed interactions was found to be significant (H1b). Controlling for employee age, affect, perceived horizontal workplace aggression and perceived coworker support, results showed a significant interaction between perceived horizontal aggression and perceived coworker social support related to work-to-family conflict, but graphing the results showed that the direction was not as hypothesized. A discussion of the nature of this interaction will be presented below. 


\section{Discussion}

Over a third of American workers have been exposed to workplace aggression (Schat et al., 2006), which can lead to many undesirable outcomes for employees and organizations. Research suggests that the antecedents and consequences of workplace aggression differ by source (Schat et al., 2006, Greenberg \& Barling, 1999). One of the main objectives of this thesis was to investigate the consequences of horizontal workplace aggression (aggression between coworkers). Research has shown that victims of workplace aggression have stronger reactions when aggressed upon by a coworker rather than an organizational outsider (Hershcovis et al., 2007). Furthermore, a recent national survey estimated that seventeen million American workers (15\% of respondents) had experienced aggression from their coworkers (Schat et al., 2006).

Organizations have acknowledged workplace aggression as a serious threat to employee and organizational health. However, this is still a fairly recent field of study, and there is much work to be done. This thesis had three specific goals: 1) explore the nature of the relationship between horizontal workplace aggression and work-family conflict; 2) to explore horizontal workplace aggression utilizing a measurement instrument that tapped into the full spectrum of interpersonal conflict; and 3) add to the body of research making connections between horizontal workplace aggression and turnover intentions.

I will begin to discuss the current project and the extent to which I was able to achieve these goals by reviewing the results of my hypothesis testing. I will then discuss 
the contributions and results of this thesis in relation to the existing literature on horizontal workplace aggression, work-family conflict, and turnover intentions, followed by a discussion of the possible explanations for null results. Next, I will review the contributions and limitations of this study. Finally, I will discuss possible avenues for further research.

\section{Horizontal Workplace Aggression and Work-Family Conflict}

It is widely recognized that workplace aggression can have very negative consequences for individual employee's work and health-related outcomes and organizational outcomes. One of the goals of this study to strengthen the evidence for the argument that workplace aggression can also have negative consequences for the employees' perceptions of work-life balance. As the first work-family researchers to employ the conservation of resources theory (Hobfoll, 1989, 2001), Grandey and Cropanzano (1999) proposed that increased work stress could lead to increased family stress. As employees juggle work demands and non-work demands, their emotional resources may be drained. Over time, stress reaction can result in decreased health, workfamily stress and thoughts of leaving one's job.

In the present study, I expected that higher levels of horizontal workplace aggression would be related to higher levels of work-to-family conflict and family-towork conflict. The results of the multiple regression analyses supported these hypotheses (H1a, H2a) and reinforce the proposal that coworkers possess a unique position in the social sphere of the workplace and can contribute to an individual's ability to negotiate 
his/her work and family lives. To my knowledge, these are novel results in the aggression and work-family conflict literature. As noted previously, few studies have linked workplace aggression to work-family conflict. Tepper (2000) found abusive supervision to be related to increased levels of work-to-family conflict and family-to-work conflict, and Jansen et al. (2003) found conflict with coworkers or a supervisor to be a risk factor for work-family conflict for men, but not for women. However, Jansen et al. (2003) employed a single-item measure of conflict, which is conceptually distinct from workplace aggression as measured by the 22-item negative acts questionnaire (Einarsen et al., 2009). My sample size and gender composition does not allow for the comparison of women to men; this is an avenue for future research.

\section{Horizontal Workplace Aggression and Turnover Intentions}

Within the context of conservation of resources theory, an individual who is experiencing stress or a loss of resources (esteem, status) due to workplace aggression may look to alleviate the cause of the strain by moving away from the stressful situation. I hypothesized that higher levels of horizontal workplace aggression would be related to higher levels of turnover intentions (H3a), as found in previous research. Hershcovis and Barling (2010) conducted a meta-analysis of 55 independent studies that specifically identified the source of workplace aggression in the study design (supervisor, coworker, or organizational outsider). The authors identified 13 studies in the literature that specifically measured the correlation between horizontal workplace aggression and turnover intentions. Together, the studies showed a strong positive relationship between 
the two constructs $(r=.23, p<.001)$. The results of the current study corresponded with these results, showing a strong correlation between horizontal workplace aggression and turnover intentions in my thesis sample $(\mathrm{r}=.37, p<.001)$, supporting H3a.

\section{Coworker Social Support as a Moderator}

I investigated coworker social support as a moderator to these relationships. Increased social support from other coworkers may have important implications for the psychological health of workers by buffering against the negative effects of horizontal aggression (Rousseau et al., 2006). Though examination of the results of this study showed that coworker social support did not moderate the relationship between horizontal aggression and family-to-work conflict or horizontal workplace aggression and turnover intentions ( $\mathrm{H} 2 \mathrm{~b}$ and $\mathrm{H} 3 \mathrm{~b}$ ), coworker social support did moderate the relationship between horizontal workplace aggression and work-to-family conflict (H1b). However, this moderation was not in the hypothesized direction (see Figure 2).

Specifically, the graph of this interaction indicates that employees who reported a low level of coworker social support experienced a higher level of work-to-family conflict under conditions of low horizontal workplace aggression than did employees who reported higher levels of coworker social support. Under conditions of higher horizontal workplace aggression, employees in this first group did not indicate that their levels of work-to-family conflict increased. Alternately, employees who reported higher levels of coworker social support indicated experiencing relatively lower levels of workto-family conflict under conditions of lower horizontal workplace aggression. When in 
conditions of higher horizontal workplace aggression, employees in this second group indicated experiencing higher levels of work-to-family conflict (see Figure 2). A simple slope analysis corroborated this interpretation. When employees reported experiencing horizontal workplace aggression it corresponded with an increased level of work-family conflict; this relationship was moderated by coworker social support, though in an unexpected direction, $t(156)=3.37, p<.001$.

This pattern of relationships indicates that coworker social support may reduce employees' experiences of work-to-family conflict under circumstances of low horizontal aggression, but is less effective under conditions of high horizontal workplace aggression. For employees who experience low coworker support, the level of work-tofamily conflict remains virtually unchanged under between conditions of low horizontal workplace aggression and high horizontal workplace aggression. These findings suggest that in conditions of low horizontal workplace aggression, coworker social support can alleviate employees' experiences of work-to-family conflict, but once the additional stressor of horizontal workplace aggression enters the work environment, coworker social support loses its ameliorating effect. While these are unexpected findings, there are few studies of relationships between coworkers that examine both positive and negative aspects of horizontal social exchanges within the same study (Chaiburu \& Harrison, 2008). There are few examples within the literature against which to compare these counterintuitive findings, though theory may aid in disentangling these results.

The buffering hypothesis (Cohen and Willis, 1985), which applied to social 
support, has been hypothesized to protect individuals with a strong social network from threats to their well-being relative to those who do not have a strong social network. Empirical support has been mixed (Beehr, 1995), if not quite confusing. This may be a result of methodological problems, differences in definitions of constructs, or an increasing awareness that the type of support received should match the type of support needed (Beehr, 1995). Important aspects of intraorganizational social support are the source of the support, timing, and type of support offered (Leather et al., 1998). Effective social support within an organization is most likely a combination of these elements.

It is necessary to infer the placement of the current study within the workplace aggression and work-family conflict literature, as I was not able to identify any studies investigating social support as moderator for the relationship between workplace aggression and work-family conflict. Although coworker social support significantly moderated the relationship between horizontal workplace aggression and work-to-family conflict, the direction of the moderation was not in the hypothesized direction. Fundamentally, the interaction demonstrates that coworker social support has the capacity to reduce work-to-family conflict, and that the introduction of workplace aggression can negatively impact employees' ability to balance work and family life.

These finding support the view that intraorganizational social support can be an important resource for employees facing exposure to workplace stressors, as has been found by researchers in the fields of both work-family conflict and workplace aggression. Leather et al. (1998) surveyed English pub employees' exposure to violence at work and 
the moderating effect of intraorganizational social support versus support originating from friends and family upon employee well-being, job satisfaction and organizational commitment. Notably, Leather et al. (1998) measured exposure to violence at work, regardless of source. Leather et al. found that the strongest intraorganizational social support moderation effects were the strongest upon employee well-being, particularly in cases where exposure to workplace aggression of a physical nature, and that perceived availability of support from family and friends did not moderate the relationship between exposure to violence at work and the employee well-being, job satisfaction or organizational commitment.

Kossek, Pichler, Bodner and Hammer (2011) used meta-analysis to investigate the employee perceptions of supervisor and organizational social support, both general and work-family specific, and the comparative relationships with work-family conflict. Utilizing 115 samples consisting of over 72,000 employees, Kossek et al. (2011) found that work-family-specific types of supervisor and organizational social support were more highly related to work-family conflict than were general types of social support. The authors noted that a lack of studies in the literature prevented the comparison of general and family-specific coworker social support from inclusion in the meta-analysis. Together, these examples illuminate the need for the type of social support receive to match the type of social support needed. While the benefits of coworker social support in the workplace are well demonstrated (Shirom et al., 2011; Ng \& Sorensen, 2008; Rousseau et al., 2006), the results of the interaction between horizontal workplace 
aggression and coworker social support in this study may reflect a discrepancy between the kind of support given and the kind of support needed by members of this sample.

\section{Potential Explanations for Null Results}

There are several important situational and methodological factors at play that may be contributing to the null findings of $\mathrm{H} 2 \mathrm{~b}$ and $\mathrm{H} 3 \mathrm{~b}$. First of all, interaction effects generally require larger sample sizes to be detected, and the sample size in this study was rather smaller than hoped. Coworker social support may indeed moderate the relationship between horizontal workplace aggression and family-to-work conflict, but the sample size may be too small to detect the effect. Future research could investigate these relationships with a larger and perhaps more diverse sample.

Secondly, the data for this study were collected during the workday at the employees' place of employment. As the surveys took place within the long-term care facilities, many participants reported fear of repercussion if their manager saw his/her survey data. Though precautions were taken to protect the confidentiality of the participants' responses, many of the employees who participated in this survey expressed concern as to whether or not I would truly be able to keep the information private. I took steps to reassure the participants that their information would be kept confidential and that I was an independent consultant strictly held in check by a human subject protection committee at a local university. Many employees chose not to participate even after learning this, expressing disbelief that ranged from cynical to hostile.

Additionally, while the long-term assisted living corporation I partnered with to 
collect this data has a relatively low turnover rate for this industry (roughly $65 \%$ turnover per year), this does not correspond to the rate of turnover intentions reported in the surveys. Together, this leads me to believe that a severe amount of underreporting of turnover intentions occurred in this data collection, perhaps due to fear related to the possibility of breach of confidentiality mentioned above. I had surprisingly high interest rate when participants were offered the chance to mail in their surveys after being consented in person. Several individuals who did not at first consent to participant reconsidered upon learning that they did not need to fill out the surveys on site. Future research may take a different approach to data collection, such as offering a selfaddressed stamped envelope when initially introducing the study material.

\section{Contributions and Limitations}

The study of workplace aggression is a fairly young area of study in the field of industrial and organizational psychology, and is still in the early stages of defining constructs, relationships, pertinent moderators and mediators, and methods for study. Following the recommendations of Hershcovis (2011), I proceeded to conceptualize negative interactions at work as workplace aggression, in keeping with researchers who are promoting a unification of construct terms in this field. This thesis contributed to the literature in three primary ways, by: 1) expanding our understanding of the nature of the relationship between horizontal workplace aggression and work-family conflict; 2) measuring horizontal workplace aggression utilizing a measurement instrument that tapped into the full spectrum of interpersonal conflict; and 3) adding to the limited body 
of research measuring both positive and negative aspects of horizontal relationships within the same study.

Hershcovis proposed three challenges to researchers as the field moves forward: territoriality of researchers over their own constructs, the actor's perspective, and methods and measures. Two of these challenges were included to a degree in the present study. First of all, Hershcovis (2011) proposed that future research should investigate such questions as task-interdependence and how perpetrator/target relationships (p.514) affect target-specific aggression. In studying low-wage shift workers, I explored the possible connection between horizontal workplace aggression and work-family conflict among coworkers in an employee population with a high degree of dependency between employees to accomplish work-related tasks, thus specifying the actor's perspective. The findings of this study indicate that workplace aggression from coworkers has a significant and positive relationship with work-to-family conflict and family-to-work conflict. While past studies have investigated the relationship between workplace aggression originating from a supervisor (Tepper, 2000) with work-family conflict, this study specified aggression originating from a coworker in a high-dependency work environment.

While there were difficulties encountered in recruiting employees in a highdependency environment during work hours, the data collection technique employed lead to an excellent response rate and thus my sample population included participants to whom I would not have had access had I recruited through email, mail or telephone calls. As reported by representatives of the participating organization, a large percentage of the 
employees do not have access to the Internet in their homes. Some level of cooperation was required between the nursing staff for CNAs to have time to fill out the surveys during paid time, as stipulated by my research agreement with the participating organization. As discussed, members of the potential sample population felt a serious level of distrust towards the management of the assisted living facilities, with a few exceptions. As I have worked as a CNA and medical assistant for many years and was not an employee of the organization, I was able to establish some level of trust with those who decided to participate. While I stressed the voluntary nature of the study to emphasize that no staff member should feel pressured or coerced into participating, many initially reluctant CNAs decided to participate upon learning my motivation for studying the topic of this thesis. I thus feel confident that the results of this study were less affected by self-selection sampling bias as a result of this recruitment method. Although this does not represent a primary contribution of this study, I feel that the high level of the participation within the sample population is noteworthy in this industry.

The second contribution of this study is related to measurement of the construct of workplace aggression. Hershcovis (2011) indicated that many existing survey measures ask participants about "someone at work" when inquiring about workplace aggression. Additionally, many studies use very brief and incomplete measurements of workplace aggression that do not encompass the full spectrum of negative personal interactions. For example, Haines et al. (2006) employed data (collected for a larger study) that had three questions referring to aggression at work. The three questions inquired as to whether or 
not the participant had experienced acts of physical violence, intimidation or unwanted actions of a sexual nature within the last year at work. One of the recommendations for future research by Haines et al. (2006) and Hershcovis (2011) was to explore horizontal workplace aggression utilizing a measurement instrument that tapped into the full spectrum of interpersonal conflict.

I attempted to fulfill this call by employing the Negative Acts Questionnaire (Einarsen et al., 2009), which has been internationally validated and includes twenty-two questions on specific acts of workplace aggression. I tailored the questionnaire to refer to coworkers specifically, and reinforced this concept verbally with participants. The Negative Acts Questionnaire has the additional benefit of enveloping three separate subscales within one larger overall measure of workplace aggression: work-related aggression (related to work tasks), person-related aggression (related to personal interactions), and physically-intimidating aggression (ranging from throwing of objects, up to and including physical violence). For this sample, there was no statistically significant difference in fit between the parsimonious model wherein workplace aggression was conceptualized as the entire twenty-two-item questionnaire and a model in which the three types of workplace aggression were separated. For the sake of parsimony in this study, I thus retained the complete measure. However, I will have the option in future studies to focus on any of the three subscales of aggression.

Third, this study adds to the limited body of research that examines horizontal (also referred to as lateral) relationships in the workplace, and the minute number of 
studies that explore both the positive and negative aspects of these relationships together in one study. Chaiburu and Harrison, authors of a 2008 conceptual synthesis and metaanalysis on coworker effects on employee work outcomes, found a fragmented literature largely couched in theory that originated to explain organizational leader-member relationships. While they found a number of primary investigations examining lateral relationships, relatively little synthesis of theory had been achieved. Most of the research reviewed for the meta-analysis was focused on either positive or negative interactions with coworkers, with either "prosocial or counterproductive outcomes" (p. 1096). The current research attempts to bridge this gap by examining both positively and negatively valenced behaviors from coworkers.

In pursuit of this aim, I uncovered a counterintuitive moderation effect within my sample. I expected to find that employees who were experiencing horizontal workplace aggression would report increased levels of work-to-family conflict, but that this relationship would be ameliorated if they were also reporting high levels of coworker support. It is reasonable to predict that an employee who is experiencing stress or loss of resources (be it personal characteristics or energies) may seek to protect these resources or acquire them elsewhere. In line with Hobfoll's conservation of resource theory (1989, 2001), stress can be a reaction when resources (self-esteem, time) are lost or perceived to be threatened. When an employee is experiencing workplace aggression and is faced with loss of resources, it might be expected that the employee may seek resources from other coworkers to prevent the burnout that may result from loss of resources while negotiating 
both family and work roles (Grandey and Cropanzano, 1999). However, the moderation results were counter to the expected direction. It may be beneficial in future research to disentangle the sources of the social support from the sources of aggression to explain these findings.

Though this research has potentially exciting findings, there are also important limitations to note. First and foremost, the data for this study were cross-sectional, which does not allow for any inference of causality. Additionally, all the data came from selfreport surveys, which can be affected by response bias as well as mono-method bias.

Furthermore, the small sample size may have limited my ability to detect effects. Lack of power should be considered as a possible reason for null results in moderated multiple regression (Agiunis \& Stone-Romero, 1997). Perhaps coworker social support does moderate the relationship between family-to-work conflict, but there is not the power to detect the relationship in this study.

Finally, collection of data from facilities belonging to one company within one specific industry will limit the generalizability of results found in this study. In addition, sample characteristics (e.g., $88 \%$ female), though this was formed from an $89 \%$ response rate, does give cause for concern in regards to a biased sample. However, I chose this sample specifically because I wanted to work within the long-term assisted-living industry, which generally has a very high percentage of female employees (Polzer, 2012), so it was to be expected. 


\section{Future Research}

More research is needed to clarify the processes at work in this study. As the nature of this thesis was highly exploratory, such research could include clarifying the role of different types of social support. For example, how does instrumental coworker social support differ from informational coworker social support in relation to horizontal aggression and work-to family conflict? Do different types of support affect or correspond with different types of workplace aggression? Does social support from a supervisor affect the relationship between horizontal aggression and work-family conflict? Research in these areas may help clarify the unique contribution of different sources and types of support.

Future research could investigate the longitudinal relationships between horizontal workplace aggression, work-family conflict and turnover intentions. In line with the conservation of resources theory (Hobfoll, 1989, 2001), individuals experiencing resource loss may be at greater risk for future resource loss unless they are somehow able to reinvest or regain resources. Multiple data points within a data collection would be better suited to track the participants' perceptions of gain or loss of resources over a period of time and could illuminate the process through which horizontal workplace aggression affects work-family conflict and turnover intentions.

Future research could include multiple organizations to increase the power of analyses and practical applicability. It would be of particular interest to me to compare a high-dependency work environment, such as those within many healthcare facilities, to a 
low-dependency work environments, such as a call center. While call centers have their own challenges (perhaps including aggression from customers), employees are not as dependent on one another to complete job tasks, and thus may not feel the effects of horizontal aggression as acutely as an employee who cannot escape from the social situation and still continue to be successful at his/her job.

Self-report surveys are not ideal; future research should attempt to limit the mono-method bias by collecting data from several sources. An improvement to study design might include data collection from organizational observers, coworkers, managers, or employee family members. Future research could also improve upon the current study by including objective measures of employee biological stress, such as cortisol in the saliva, blood pressure, or sleep patterns.

Perhaps most intriguing, research on horizontal aggression prevention and intervention is needed. Schat and Kelloway (2005) suggest ways in which organizations can meet the challenges presented by workplace aggression. Crisis response systems should be put into place, as research has shown the immediate and long-term effects of experiencing workplace aggression to be severe (LeBlanc \& Kelloway, 2002; Barling and McEwen, 1992). Additional training programs can provide employees and managers with skills to cope effectively with workplace aggression. These avenues represent rich avenues for future research, especially in the realm of intervention work.

While protections against workplace aggression are perhaps to enforce, administrators and supervisors may be in breach of legal obligations to employees if they 
fail to protect them from workplace aggression (Einarsen, \& Raknes, 1997). While this point underpins the legal necessity of the responsibilities of organizations to advocate for employees experiencing workplace aggression, organizations can benefit in other ways by creating a culture where aggression is discouraged, such as increased employee job satisfaction (Lapierre et al., 2005) and decreased employee turnover intentions (Budd et al., 1996).

\section{Conclusion}

This study is based on the hope that by reducing the stressors in an individual's work environment, the organization can help reduce the negative outcomes associated with strain. In seeking to discover some of the ways in which horizontal workplace aggression occurs between health care workers, I hope to assist this and other organizations in the future with reduction of turnover. Additionally, I would like to continue to investigate ways to lower workers' experiences of work-family conflict by reducing stress as a result of horizontal aggression in their work domain through longitudinal studies employing multiple sources of data. The well-being of workers within the healthcare system of vital importance to patient and organizational outcomes, and is worthy of the attention of researchers and practitioners alike. 


\section{Table 1.}

Means, Standard Deviations, Intercorrelations and Internal Consistency Estimates of Study Variables

\begin{tabular}{|c|c|c|c|c|c|c|c|c|c|c|c|c|c|c|}
\hline & $M$ & $S D$ & 1 & 2 & 3 & 4 & 5 & 6 & 7 & 8 & 9 & 10 & 11 & 12 \\
\hline 1. Age & 34.83 & 11.91 & & & & & & & & & & & & \\
\hline $\begin{array}{l}\text { 2. Gender } \\
\text { 3. Relationship }\end{array}$ & N/A & N/A & $-0.20 *$ & & & & & & & & & & & \\
\hline $\begin{array}{l}\text { Status } \\
4 . \text { \#of }\end{array}$ & N/A & N/A & $-0.38 * *$ & -0.06 & & & & & & & & & & \\
\hline Dependents & 1.04 & 1.18 & -0.09 & -0.03 & -0.10 & & & & & & & & & \\
\hline $\begin{array}{l}\text { 5. Adult Care } \\
\text { 6. \# Hours }\end{array}$ & N/A & N/A & -0.07 & 0.06 & 0.03 & -0.08 & & & & & & & & \\
\hline $\begin{array}{l}\text { Worked } \\
7 . \text { Negative }\end{array}$ & 36.99 & 7.5 & 0.08 & 0.01 & -0.12 & 0.04 & 0.06 & & & & & & & \\
\hline $\begin{array}{l}\text { Affect } \\
\text { 8. Horizontal }\end{array}$ & 1.84 & .74 & 0.02 & -0.08 & 0.01 & -0.11 & -0.03 & $0.19 *$ & $(.79)$ & & & & & \\
\hline $\begin{array}{l}\text { Aggression } \\
\text { 9. Coworker }\end{array}$ & 1.75 & .76 & -0.07 & -0.07 & 0.01 & -0.01 & -0.07 & 0.13 & $0.53 * *$ & $(.95)$ & & & & \\
\hline $\begin{array}{l}\text { Social Support } \\
10 . \text { Work to }\end{array}$ & 3.55 & .77 & 0.04 & 0.13 & -0.06 & $-0.24 *$ & 0.14 & -0.01 & $-0.27 * *$ & $-0.42 * *$ & $(.86)$ & & & \\
\hline $\begin{array}{l}\text { Family Conflict } \\
\text { 11. Family to }\end{array}$ & 2.62 & 1.10 & $-0.17^{*}$ & -0.10 & 0.13 & -0.04 & -0.09 & 0.04 & $0.29 * *$ & $0.34 * *$ & $-0.31 * *$ & $(.93)$ & & \\
\hline $\begin{array}{l}\text { Work Conflict } \\
\text { 12. Turnover }\end{array}$ & 1.84 & .82 & 0.01 & -0.07 & -0.02 & -0.04 & 0.00 & 0.04 & $0.27 * *$ & $0.50 * *$ & $-0.24 * *$ & $0.47 * *$ & $(.89)$ & \\
\hline Intentions & 2.61 & 1.30 & $-0.32 * *$ & -0.08 & $0.26^{* *}$ & 0.10 & -0.05 & -0.07 & $0.28 * *$ & $0.35 * *$ & $-0.38 * *$ & $0.45 * *$ & $0.20^{*}$ & $(.96)$ \\
\hline
\end{tabular}

*Indicates significance at the $p<.05$ level, ** Indicates significance at the $p<.01$ level, Internal consistency estimates are in parenthesis on the diagonal. 
Table 2.

Standard Multiple Regression Results Predicting Work-to-Family Conflict from Control Variables

\begin{tabular}{lcccc}
\hline \multicolumn{1}{c}{ Control Variable } & $\mathrm{B}$ & $\mathrm{SE}$ & $\beta$ \\
\hline Age & 0.00 & 0.00 & -0.01 \\
Gender & 0.00 & 0.01 & -0.04 \\
Relationship status & -0.17 & 0.14 & -0.10 \\
\# of Dependents under 18 & 0.06 & 0.05 & 0.09 \\
Adult care & -0.02 & 0.01 & -0.02 \\
\# Hours worked per week & 0.00 & 0.01 & -0.02 \\
Negative affect & $0.35^{* * *}$ & 0.09 & 0.33 \\
\hline
\end{tabular}

${ }^{*} p<.05 .{ }^{*} p<.01 . * * * p<.001$.

Table 3.

Standard Multiple Regression Results Predicting Family-to-Work Conflict from Control Variables

\begin{tabular}{lccc}
\hline \multicolumn{1}{c}{ Control Variable } & B & SE & $\beta$ \\
\hline Age & 0.00 & 0.01 & -0.01 \\
Gender & -0.01 & 0.01 & -0.04 \\
Relationship status & -0.17 & 0.14 & -0.10 \\
\# of Dependents under 18 & 0.06 & 0.05 & 0.09 \\
Adult care & -0.02 & 0.14 & -0.01 \\
\# Hours worked per week & 0.00 & 0.01 & -0.02 \\
Negative affect & $0.35^{* * *}$ & 0.09 & 0.33 \\
\hline
\end{tabular}

$* p<.05 . * * p<.01 . * * * p<.001$. 
Table 4.

Standard Multiple Regression Results Predicting Turnover Intentions from Control Variables

\begin{tabular}{lccc}
\hline \multicolumn{1}{c}{ Control Variable } & $\mathrm{B}$ & $\mathrm{SE}$ & $\beta$ \\
\hline Age & $-0.04^{*}$ & 0.60 & -0.34 \\
Gender & -0.04 & 0.01 & -0.14 \\
Relationship status & -0.26 & 0.02 & -0.10 \\
\# of Dependents under 18 & -0.01 & 0.19 & -0.01 \\
Adult care & 0.00 & 0.20 & 0.00 \\
\# Hours worked per week & -0.02 & 0.01 & -0.12 \\
Negative affect & $0.53 * * *$ & 0.13 & 0.32 \\
\hline
\end{tabular}

$* p<.05 . * * p<.01 . * * * p<.001$. 
Table 5.

Hierarchical Regression models tested

\begin{tabular}{|c|c|c|}
\hline Regression & Hypotheses Tested by Step & Dependent Variable \\
\hline 1 & 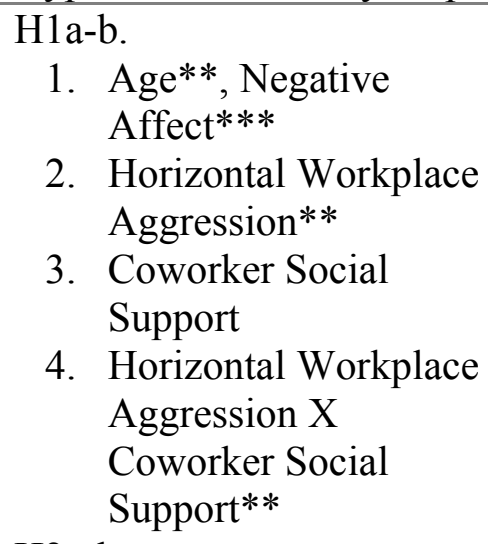 & Work-to-Family Conflict \\
\hline 2 & 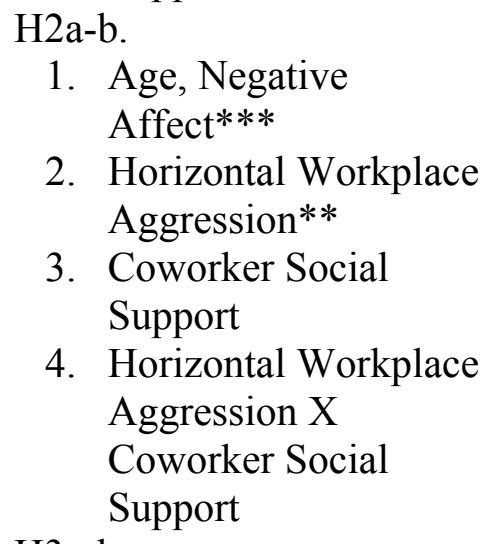 & Family-to-Work Conflict \\
\hline 3 & $\begin{array}{l}\text { H3a-b. } \\
\text { 1. Age***, Negative } \\
\text { Affect*** } \\
\text { 2. Horizontal Workplace } \\
\text { Aggression** } \\
\text { 3. } \text { Coworker Social } \\
\text { Support** } \\
\text { 4. Horizontal Workplace } \\
\text { Aggression X } \\
\text { Coworker Social } \\
\text { Support }\end{array}$ & Turnover Intentions \\
\hline
\end{tabular}


Table 6.

Summary of Regression Analysis for Testing Hypothesis 1: The relationship between horizontal workplace aggression on work-to-family conflict, moderated by coworker social support.

\begin{tabular}{|c|c|c|c|}
\hline Variable & $\Delta \mathbf{R}^{2}$ & F Change & $\beta$ \\
\hline \multicolumn{4}{|l|}{ Hierarchical Regression } \\
\hline Step 1: Control Variables & 0.13 & $11.69 * * *$ & \\
\hline Age & & & $-0.18^{*}$ \\
\hline Negative Affect & & & $0.32 * * *$ \\
\hline Step 2: DV regressed on IV & 0.04 & $6.34 *$ & \\
\hline Age & & & $-0.16^{*}$ \\
\hline Negative Affect & & & $0.19^{*}$ \\
\hline Horizontal Workplace Aggression & & & $0.22 *$ \\
\hline Step 3: Add moderator to step 2 model & 0.01 & 2.4 & \\
\hline Age & & & $-0.16^{*}$ \\
\hline Negative Affect & & & $0.18^{*}$ \\
\hline Horizontal Workplace Aggression & & & 0.18 \\
\hline Coworker Social Support & & & -0.13 \\
\hline Step 4: Add interaction term to step 3 model & 0.04 & $7.43 * *$ & \\
\hline Age & & & $-0.15^{*}$ \\
\hline Negative Affect & & & $0.19 *$ \\
\hline Horizontal Workplace Aggression & & & $0.27 * *$ \\
\hline Coworker Social Support & & & -0.13 \\
\hline $\begin{array}{l}\text { Horizontal Workplace Aggression*Coworker Social } \\
\text { Support }\end{array}$ & & & $0.22 * *$ \\
\hline
\end{tabular}

${ }_{p<.05 .}^{* * p<.01 . * * * p<.001 . ~ N o t e}$ : IV $=$ Horizontal workplace aggression; Moderator $=$ Coworker social support; DV $=$ Work-to-family conflict. $\mathrm{N}=156$. 


\section{Table 7.}

Summary of Regression Analysis for Testing Hypothesis 2: The relationship between horizontal workplace aggression on family-to-work conflict, moderated by coworker social support.

\begin{tabular}{|c|c|c|c|}
\hline Variable & $\Delta \mathbf{R}^{2}$ & $\begin{array}{c}\text { F } \\
\text { Change }\end{array}$ & $\beta$ \\
\hline \multicolumn{4}{|l|}{ Hierarchical Regression } \\
\hline Step 1: Control Variables & 0.09 & $7.11 * *$ & \\
\hline Age & & & 0.01 \\
\hline Negative Affect & & & $0.29 * * *$ \\
\hline Step 2: DV regressed on IV & 0.19 & $39.67 * * *$ & \\
\hline Age & & & 0.04 \\
\hline Negative Affect & & & 0.00 \\
\hline Horizontal Workplace Aggression & & & $0.52 * * *$ \\
\hline Step 3: Add moderator to step 2 model & 0.00 & 0.01 & \\
\hline Age & & & 0.04 \\
\hline Negative Affect & & & 0.00 \\
\hline Horizontal Workplace Aggression & & & $0.52 * * *$ \\
\hline Coworker Social Support & & & -0.01 \\
\hline Step 4: Add interaction term to step 3 model & 0.01 & 2.11 & \\
\hline Age & & & 0.05 \\
\hline Negative Affect & & & 0.00 \\
\hline Horizontal Workplace Aggression & & & $0.56^{* * *}$ \\
\hline Coworker Social Support & & & -0.01 \\
\hline Horizontal Workplace Aggression*Coworker & & & \\
\hline Social & & & 0.11 \\
\hline Support & & & \\
\hline
\end{tabular}

$* p<.05 .{ }^{*} p<.01 . * * * p<.001$. Note $:$ IV $=$ Horizontal workplace aggression; Moderator $=$ Coworker social support; DV = Family-to-work conflict. $\mathrm{N}=156$. 
Table 8.

Summary of Regression Analysis for Testing Hypothesis 3: The relationship between horizontal workplace aggression on turnover intentions, moderated by coworker social support.

\begin{tabular}{|c|c|c|c|}
\hline Variable & $\Delta \mathbf{R}^{2}$ & F Change & $\beta$ \\
\hline \multicolumn{4}{|l|}{ Hierarchical Regression } \\
\hline Step 1: Control Variables & 0.20 & $18.84 * * *$ & \\
\hline Age & & & $-0.33 * * *$ \\
\hline Negative Affect & & & $0.31 * * *$ \\
\hline Step 2: DV regressed on IV & 0.05 & $9.47 * *$ & \\
\hline Age & & & $-0.31 * * *$ \\
\hline Negative Affect & & & 0.17 \\
\hline Horizontal Workplace Aggression & & & $0.26^{* *}$ \\
\hline Step 3: Add moderator to step 2 model & 0.05 & $10.83^{* *}$ & \\
\hline Age & & & $-0.31 * * *$ \\
\hline Negative Affect & & & 0.14 \\
\hline Horizontal Workplace Aggression & & & $0.17^{*}$ \\
\hline Coworker Social Support & & & $-0.25 * *$ \\
\hline Step 4: Add interaction term to step 3 model & 0.01 & 1.51 & \\
\hline Age & & & $-0.30 * * *$ \\
\hline Negative Affect & & & 0.14 \\
\hline Horizontal Workplace Aggression & & & $0.21 *$ \\
\hline Coworker Social Support & & & $-0.25 * *$ \\
\hline Horizontal Workplace Aggression*Coworker Social & & & 0.09 \\
\hline
\end{tabular}

${ }^{*} p<.05 .{ }^{*} p<.01 .{ }^{*} *{ }^{*} p<.001$. Note: IV $=$ Horizontal workplace aggression; Moderator $=$ Coworker social support; DV = Turnover Intentions. $\mathrm{N}=156$. 


\section{Figure 1.}

Hypothesized Model: Horizontal workplace aggression relates to work-to-family conflict, family-to-work conflict and turnover intentions. Perceived coworker support moderates these relationships such that employees who experience lower levels of coworker social support experience higher levels of work-to-family conflict, family-to-work conflict and turnover intentions.

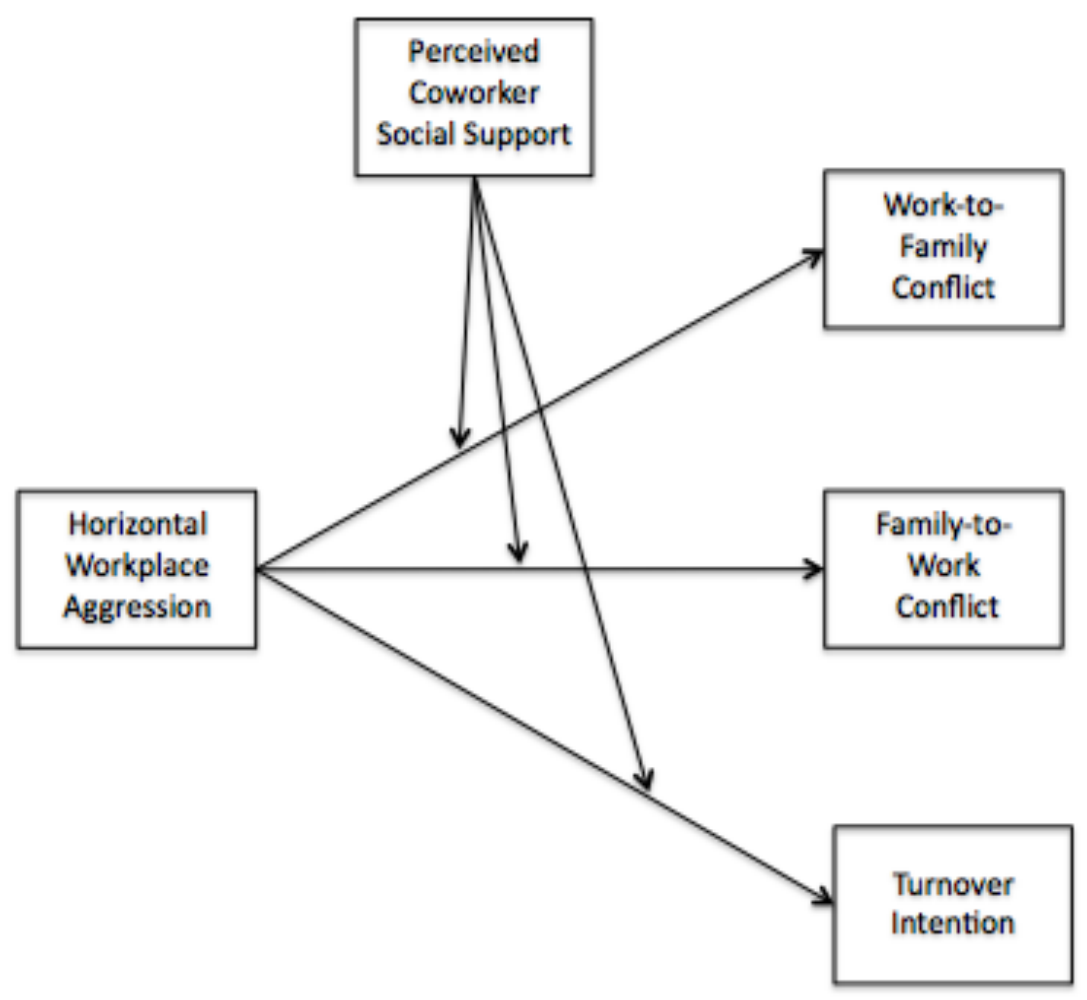




\section{Figure 2.}

Significant interaction between perceived horizontal workplace aggression and perceived coworker social support in regards to work-to-family conflict.

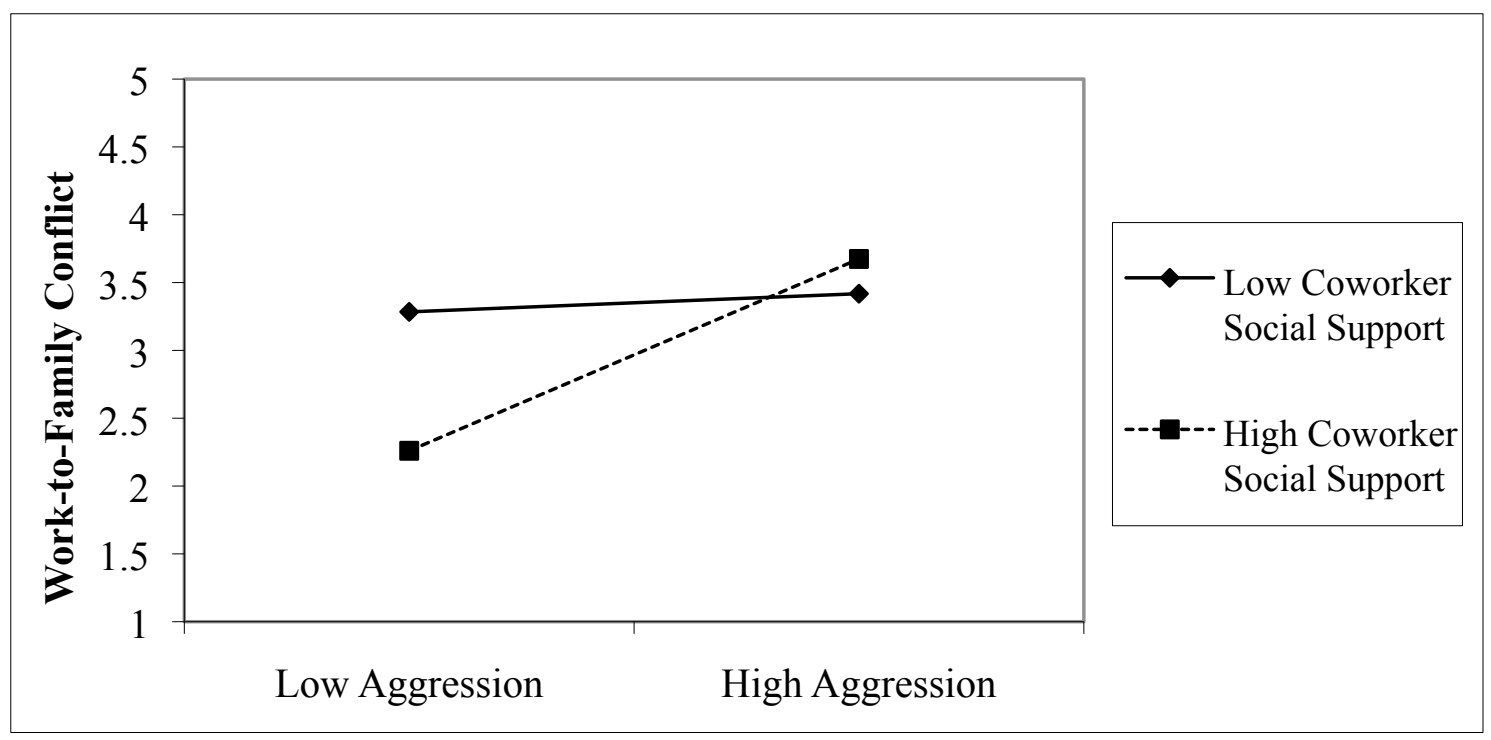




\section{References}

Aguinis, H., \& Stone-Romero, E. F. (1997). Methodological artifacts in moderated multiple regression and their effects on statistical power. Journal of Applied Psychology, 82, 192 -206.

Allen, T. D., Herst, D. E. L., Bruck, C. S., \& Sutton, M. (2000). Consequences associated with work-to-family conflict: A review and agenda for future research. Journal of Occupational Health Psychology, 5, 278-308.

Andersson, L. M., \& Pearson, C. M. (1999). Tit for tat? The spiraling effect of incivility in the workplace. Academy of Management Review, 24, 452-471.

Barcikowski, R. S. (1981). Statistical power with group mean as the unit of analysis. Journal of Educational Statistics, 6, 267-285.

Barling, J., Dupre, K. E., \& Kelloway, E. K. (2009). Predicting workplace aggression and violence. Annual Review of Psychology, 60, 671.

Barling, J., \& MacEwen, K. E. (1992). Linking work experiences to facets of marital functioning. Journal of Organizational Behavior, 13, $573-582$.

Barnett, R. C. \& Hall, D. T. (2007). The silver lining in shift work: Can your organization take advantage of it? Organizational Dynamics, 36(4), 404-417.

Baron, R. A., Neuman, J. H., \& Geddes, D. (1999). Social and personal determinants of workplace aggression: evidence for the impact of perceived injustice and the Type A behavior pattern. Aggressive Behavior, 25(4), 281.

Beehr, T. A. (1995). Psychological stress in the workplace. London: Routledge.

Bellavia, G., Frone, M. (2005). Work-family conflict. In J. Barling, EK Kelloway \& M. 
Frone (Eds.) Handbook of work stress. Thousand Oaks, CA: Sage.

Björkqvist, K., Österman, K., \& Lagerspetz, K. M. J. (1994). Sex differences in covert aggression among adults. Aggressive Behavior, 20(1), 27-33.

Bowling, N. A., Beehr, T. A., Bennett, M. M., \& Watson, C. P. (2010). Target personality and workplace victimization: A prospective analysis. Work and Stress, 24(2), 140-158.

Bureau of Labor Statistics. (2009). National census of fatal occupational injuries. Washington, DC: Bureau of Labor Statistics.

Budd, J. W., Arvey, R. D., \& Lawless, P. (1996). Correlates and consequences of workplace violence. Journal of Occupational Health Psychology, 1, 197-210.

Buss, A. H. (1963). Physical aggression in relation to different frustrations. Journal of Abnormal and Social Psychology, 67, 1-7.

Byron, K. (2005). A meta-analytic review of work-family conflict and its antecedents. Journal of Vocational Behavior, 67(2), 169-198.

Caplan, R. D., Cobb, S., French, J. R. P., Van Harrison, R., \& Pinneau, S. R. (1980). Job demands and worker health. Ann Arbor: University of Michigan, Institute for Social Research.

Chiaburu, D. S., \& Harrison, D. A. (2008). Do peers make the place? Conceptual synthesis and meta-analysis of coworker effects on perceptions, attitudes, OCBs, and performance. Journal of Applied Psychology, 93(5), 1082-1103.

Cohen, S., \& Willis, T. A. (1985). Stress, social support and the buffering hypothesis. Psychological Bulletin, 98, 310-357. 
Costa, G. (2003). Factors influencing health of workers and tolerance to shift work. Theoretical Issues in Ergonomics Science, 4(3), 263-288.

Decker, F. H., Harris-Kojetin, L. D., \& Bercovitz, A. (2009). Intrinsic job satisfaction, overall satisfaction, and intentions to leave the job among nursing assistants in nursing homes. Gerontologist, 49(5), 596-610.

Demerouti, E., Bakker, A. B., \& Bulters, A. J. (2004). The loss spiral of work pressure, work-home interference and exhaustion: Reciprocal relations in a three-wave study. Journal of Vocational Behavior,64(1), 131-149.

Douglas, S. C., \& Martinko, M. J. (2001). Exploring the role of individual differences in the prediction of workplace aggression. The Journal of Applied Psychology, 86, 4, 547-59.

Duffy, M., \& Sperry, L. (2007). Workplace mobbing: individual and family health consequences. The Family Journal, 15(4), 398-404.

Eby, L.T., Casper, W.J., Lockwood, A., Bordeaux, C., \& Brinley, A. (2005). Work and family research in IO/OB: Content analysis and review of the literature (19802002). Journal of Vocational Behavior, 66, 124-197.

Edwards, J. R., \& Rothbard, N. P. (2000). Mechanisms linking work and family: Clarifying the relationship between work and family constructs. Academy of Management Review, 25(1), 78-199.

Einarsen, S. (1999). The nature and causes of bullying at work. International Journal of Manpower, 20, 16-27. 
Einarsen, S., \& Raknes, B. I. (1997). Harassment in the workplace and the victimization of men. Violence and Victims, 12(3), 247-263.

Einarsen, S., Notelaers, G., \& Hoel, H. (2009). Measuring exposure to bullying and harassment at work: Validity, factor structure and psychometric properties of the negative acts questionnaire-revised. Work and Stress, 23(1), 24-44.

Faul, F., Erdfelder, E., Lang, A.-G., \& Buchner, A. (2007). G*Power 3: A flexible statistical power analysis program for the social, behavioral, and biomedical sciences. Behavior Research Methods, 39, 175-191.

Fields, D. L. (2002). Taking the measure of work: A guide to validated scales for organizational research and diagnosis. Thousand Oaks, Calif: Sage.

Findley, D., and Richardson, B. (2000). Draft final report: CNA recruitment and retention project evaluation. In "Certified nursing assistant recruitment and retention pilot project final report," Iowa Caregivers Association for the Iowa Department of Human Services.

Glanz, K., Rimer, B. K., Viswanath, K., \& Ebooks Corporation. (2008). Health behavior and health education: Theory, research, and practice. Hoboken: John Wiley \& Sons, Inc.

Grandey, A. A., \& Cropanzano, R. (1999). The conservation of resources model applied to work-family conflict and strain. Journal of Vocational Behavior, 54, 350-370.

Greenberg, L., \& Barling, J. (1999). Predicting employee aggression against coworkers, subordinates and supervisors: The role of person behaviors and perceived workplace factors. Journal of Organizational Behavior , 20(6), 897-913. 
Griffeth, R. W., Hom, P. W., \& Gaertner, S. (2000). A meta-analysis of antecedents and correlates of employee turnover: Update, moderator tests, and research implications for the next millenium. Journal of Management, 26(3), 463-488.

Haber, M., Cohen, J., Lucas, T., \& Baltes, B. (2007). The relationship between selfreported received and perceived social support: A meta-analytic review. American Journal of Community Psychology, 39, 1-2.

Haines, V. Y., Marchand, A., \& Harvey, S. (2006). Crossover of workplace aggression experiences in dual-earner couples. Journal of Occupational Health Psychology, 11(4), 305-14.

Harris-Kojetin, L., Lipson, D., Fielding, J., Kiefer, K., \& Stone, R. I. (2004). Recent findings on frontline long-term care workers: A research synthesis 1999-2003. Washington, DC: Institute for the Future of Aging Services.

Harvey, M., Heames, J., Richey, R., \& Leonard, N. (2006). Bullying: From the playground to the boardroom. Journal of Leadership \& Organizational Studies, 12(4), 1-11.

Harvey, S., \& Keashly, L. (2003). Predicting the risk for aggression in the workplace: Risk factors, self-esteem and time at work. Social Behaviour and Personality, 31, 807-814.

Hegney, D., Plank, A., \& Parker, V. (2003). Workplace violence in nursing in Queensland, Australia: A self-reported study. International Journal of Nursing Practice, 9(4), 261-268.

Hershcovis, M. S. (2011). "Incivility, social undermining, bullying...oh my!": A call to 
reconcile constructs within workplace aggression research. Journal of Organizational Behavior, 32(3), 499-519.

Hershcovis, M. S., \& Barling, J. (2010). Towards a multi-foci approach to workplace aggression: A meta-analytic review of outcomes from different perpetrators. Journal of Organizational Behavior, 48(1), 24-44.

Hershcovis, M. S., Turner, N., Barling, J., Arnold, K. A., Dupré, K. E., Inness, M., ... Sivanathan, N. (2007). Predicting workplace aggression: A meta-analysis. Journal of Applied Psychology, 92, 228-238.

Hobfoll, S. E. (2001). The influence of culture, community, and the nested-self in the stress process: Advancing conservation of resources theory. Applied Psychology, 50(3), 337-421.

Hobfoll, S. E. (1989). Conservation of resources: A new attempt at conceptualizing stress. American Psychologist, 44(3), 513-524.

Hobfoll, S. E., \& Lilly, R. S. (1993). Resource conservation as a strategy for community psychology. Journal of Community Psychology, 21(2), 128-148.

Hom, P. W., Griffeth, R. W., \& Sellaro, C. L. (1984). The validity of Mobley's (1977) model of employee turnover. Organizational Behavior and Human Performance, $34,141-174$.

Jansen, N. W. H., Kant, I. K., Kristensen, T. S., \& Nijhuis, F. J. N. (2003). Antecedents and consequences of work-family conflict: A prospective cohort study. Journal of Occupational and Environmental Medicine, 45(5), 479-491.

Kahn, R. L., Byosiere, P. (1992). Stress in organizations. In M. D. Dunnette and L. M. 
Hough (Eds.), Handbook of Industrial and Organizational Psychology (2nd Ed.,Vol. 3, pp. 571-650). Palo Alto, California: Consulting Psychologist Press. Katz, D. \& Kahn, R. (1978). The social psychology of organizations (2nd Ed.). New York: John Wiley \& Sons.

Keashly, L., \& Jagatic, K. (2003). By any other name: American perspectives on workplace bullying. In S. Einarsen, H. Hoel, D. Zapf, \& C. Cooper (Eds.), Bullying and emotional abuse in the workplace: International perspectives in research and practice (pp. 31-61). London: Taylor Francis.

Keashly, L. (1998). Emotional abuse in the workplace: Conceptual and empirical issues. Journal of Emotional Abuse, 1, 85-117.

Kelloway, E. K., Gottlieb, B. H., \& Barham, L. 1999. The source, nature, and direction of work and family conflict: A longitudinal investigation. Journal of Occupational Health Psychology, 4, 337-346.

Kossek, E. E., Pichler, S., Bodner, T., \& Hammer, L. B. (2011). Workplace social support and work-family conflict: A meta-analysis clarifying the influence of general and work-family-specific supervisor and organizational support. Personnel Psychology, 64(2), 289-313.

LeBlanc, M. M., \& Kelloway, E. K. (2002). Predictors and outcomes of workplace violence and aggression. Journal of Applied Psychology, 87, 444-453.

Lapierre, L. M., Spector, P. E., \& Leck, J. D. (2005). "Sexual versus nonsexual workplace aggression and victims' overall job satisfaction: A meta-analysis." Journal of Occupational Health Psychology, 10, 155-169. 
Lazarus, R. L., \& Folkman, S. (1984). Stress, Appraisal and Coping. New York: Springer.

Leather, P., Lawrence, C., Beale, D., Cox, T., \& Dickson, R. (1998). Exposure to occupational violence and the buffering effects of intra-organizational support. Work \& Stress, 12, 161-178.

Leymann, H. (1996). The content and development of mobbing at work. European Journal of Work and Organizational Psychology, 5(2), 165-184.

Martinko, M. J., \& Zellars, K. L. (1998). Toward a theory of workplace violence and aggression: A cognitive appraisal perspective. Monographs in Organizational Behavior and Industrial Relations, 23, 1-42.

McKenna, B. G., Smith, N. A., Poole, S. J., \& Coverdale, J. H. (2003). Horizontal violence: experiences of registered nurses in their first year of practice. Journal of Advanced Nursing, 42(1), 90-96.

Mobley, W. (1977). Intermediate linkages in the relationship between job satisfaction and employee turnover. Journal of Applied Psychology, 62, 237-240

Namie, G., \& Namie, R. (2000). The bully at work: What you can do to stop the hurt and reclaim your dignity on the job. Naperville, IL: Sourcebooks.

Netemeyer, R. G., Boles, J. S., \& McMurrian, R. (1996). Development and validation of work-family conflict and family-work conflict scales. Journal of Applied Psychology , 81(4), 400-410.

Neuman, J. H., \& Baron, R. A. (1998). Workplace violence and workplace aggression: 
Evidence concerning specific forms, potential causes, and preferred targets. Journal of Management, 24(3), 391.

Ng, T. W., \& Sorensen, K. L. (2008). Toward a further understanding of the relationships between perceptions of support and work attitudes: A meta-analysis. Group Organization \& Management, 33, 243-268.

Noelker, L., Ejaz, F., Menne, H., \& Jones, J. (2006). The impact of stress and support on nursing assistant satisfaction with supervision. The Journal of Applied Gerontology, 25(4), 307-323.

Northwestern National Life. (1993). Fear and violence in the workplace: A survey documenting the experience of American workers. Minneapolis, MN: Northwestern National Life, Employee Benefits Division.

Nyberg, A. (2010). Retaining your high performers: Moderators of the performance-job satisfation-voluntary turnover relationship. Journal of Applied Psychology, 95(3), 440-453.

O'Connell, B., Young, J., Brooks, J., Hutchings, J., \& Lofthouse, J. (2000). Nurses' perceptions of the nature and frequency of aggression in general ward settings and high dependency areas. Journal of Clinical Nursing, 9(4), 602-610.

O'Leary-Kelly, A. M., Griffin, R. W., \& Glew, D. J. (1996). Organization-motivated aggression: A research framework. Academy of Management Review, 21: 225253.

Perrucci, R., MacDermid, S., King, E., Tang, C. Y., Brimeyer, T., Ramadoss, K., Kiser, S., ... Swanberg, J. (2007). The significance of shift work: Current status and future directions. Journal of Family and Economic Issues, 28(4), 600-617. 
Polzer, K. (2012). Assisted living state regulatory review. Washington, DC: National Center for Assisted Living.

Presser, H. B. (2003a). Working in a 24/7 economy: Challenges for American families. New York: Russell Sage Foundation.

Presser, H. B. (2003b). Race, ethnic, and gender differences in nonstandard work shifts. Work and Occupations, 30(4), 412-439.

Quick, G. (2000). Horizontal aggression among Manitoba general duty/staff registered nurses: A descriptive study. Master's thesis, University of Manitoba.

Ray, E., \& Miller, K. (1994). Social support, home/work stress, and burnout: Who can help? Journal of Applied Behavioral Science, 30, 357-373.

Report of the United States Postal Service Commission on a Safe and Secure Workplace. (2000). New York, NY: National Center on Addiction and Substance Abuse at Columbia University.

Robinson, S. L., \& Bennett, R. J. (1995). A typology of deviant workplace behaviors: A multidimensional scaling study. Academy of Management Journal, 38(2), 555572.

Rodriguez-Munoz, A., Baillien, E., Moreno-Jimenez, B., \& Pastor, J. C. (2010). Crosslagged relationships between workplace bullying, job satisfaction, and engagement: Two longitudinal studies. Work \& Stress , 23(3), 225-243.

Rousseau, V., Salek, S., Aube, C., \& Morin, E. M. (2009). Distributive justice, 
procedural justice, and psychological distress: The moderating effect of coworker support and work autonomy. Journal of Occupational Health Psychology, 14(3), 305-317.

Rousseau, V., Aube, C., \& Savoie, A. (2006). Teamwork behaviors: A review and an integration of frameworks. Small Group Research, 37(5), 540-570.

Schat, A. C. H., Frone, M., Kelloway, E. K. (2006). Prevalence of workplace aggression in the U.S. workforce: Findings from a national study. In E. K. Kelloway, J. Barling, J. J. Hurrell, (Eds.), Handbook of Workplace Violence (pp. 47-90). Thousand Oaks, CA: Sage.

Schat, A. C. H., Kelloway, E. K. (2005). Workplace violence. In J. Barling, E. K. Kelloway, M. Frone, (Eds.), Handbook of Work Stress (pp. 189-218). Thousand Oaks, CA: Sage

Schat, A. C. H., \& Kelloway, E. K. (2000). Effects of perceived control on the outcomes of workplace aggression and violence. Journal of Occupational Health Psychology, 5, 386-402.

Selye, H. (1950). The physiology and pathology of exposure to stress. Montreal: Acta.

Shirom, A., Toker, S., Alkaly, Y., Jacobson, O., \& Balicer, R. (2011). Work-based predictors of mortality: A 20-year follow-up of healthy employees. Health Psychology, 30(3), 268-275.

Spector, P. E. (1991). Confirmatory test of a turnover model utilizing multiple data sources. Human Performance, 4(3), 221-230. 
Strazdins, L., Korda, R. J., Lim, L. Y., Broom, D. H. \& D’Souza, R. M. (2004). Around-the-clock: Parent work schedules and children's well-being in a 24-h economy. Social Science \& Medicine, 59(7), 1517-1527.

Tabachnick, B. G., \& Fidell, L. S. (2006). Using multivariate statistics (5th ed.). Boston: Bearson / Allyn and Bacon.

Tepper, B. J. (2000). Consequences of abusive supervision. Academy of Management Journal, 43(2), 178-190.

Tetrick, L. E., \& Quick, J. C. (2011). Overview of occupational health psychology: Public health in occupational settings. In J. C. Quick, \& L. E. Tetrick (Eds.), in Handbook of occupational health psychology (pp. 3-20). Washington, DC: American Psychological Association.

Thompson, E. (2007). Development and validation of an internationally reliable shortform of the Positive and Negative Affect Schedule (PANAS). Journal of CrossCultural Psychology, 38(2) 227-242.

Westman, M. (2001). Stress and strain crossover. Human Relations, 54, 717-751

Watson, D. (1988). The vicissitudes of mood measurement: Effects of varying descriptors, time frames, and response formats on measures of positive and negative affect. Journal of Personality and Social Psychology, 55(1), 128-141. 


\section{Appendix A \\ Negative Acts Questionnaire - Revised (NAQ-R)}

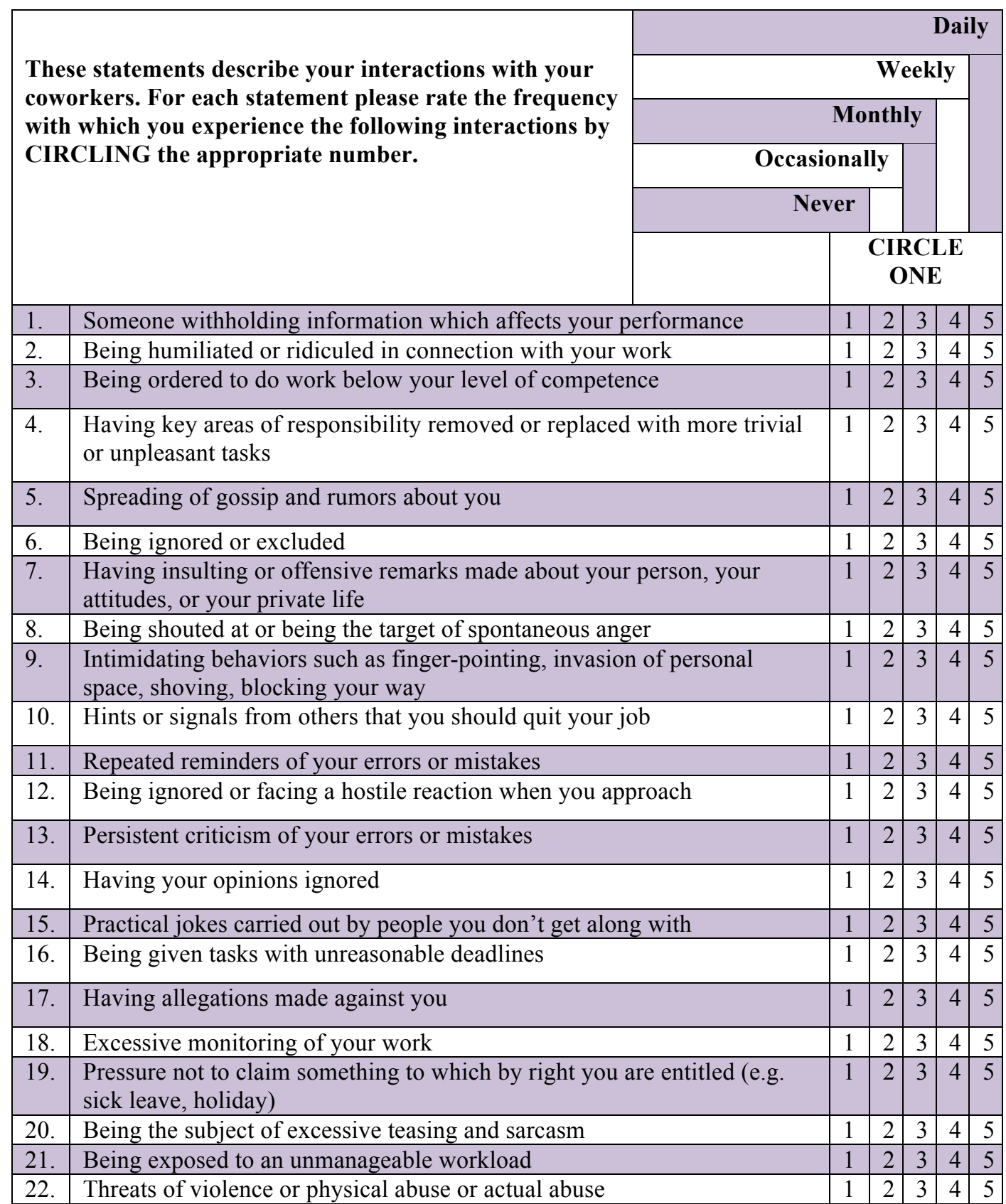




\section{Appendix B \\ Work-Family Conflict}

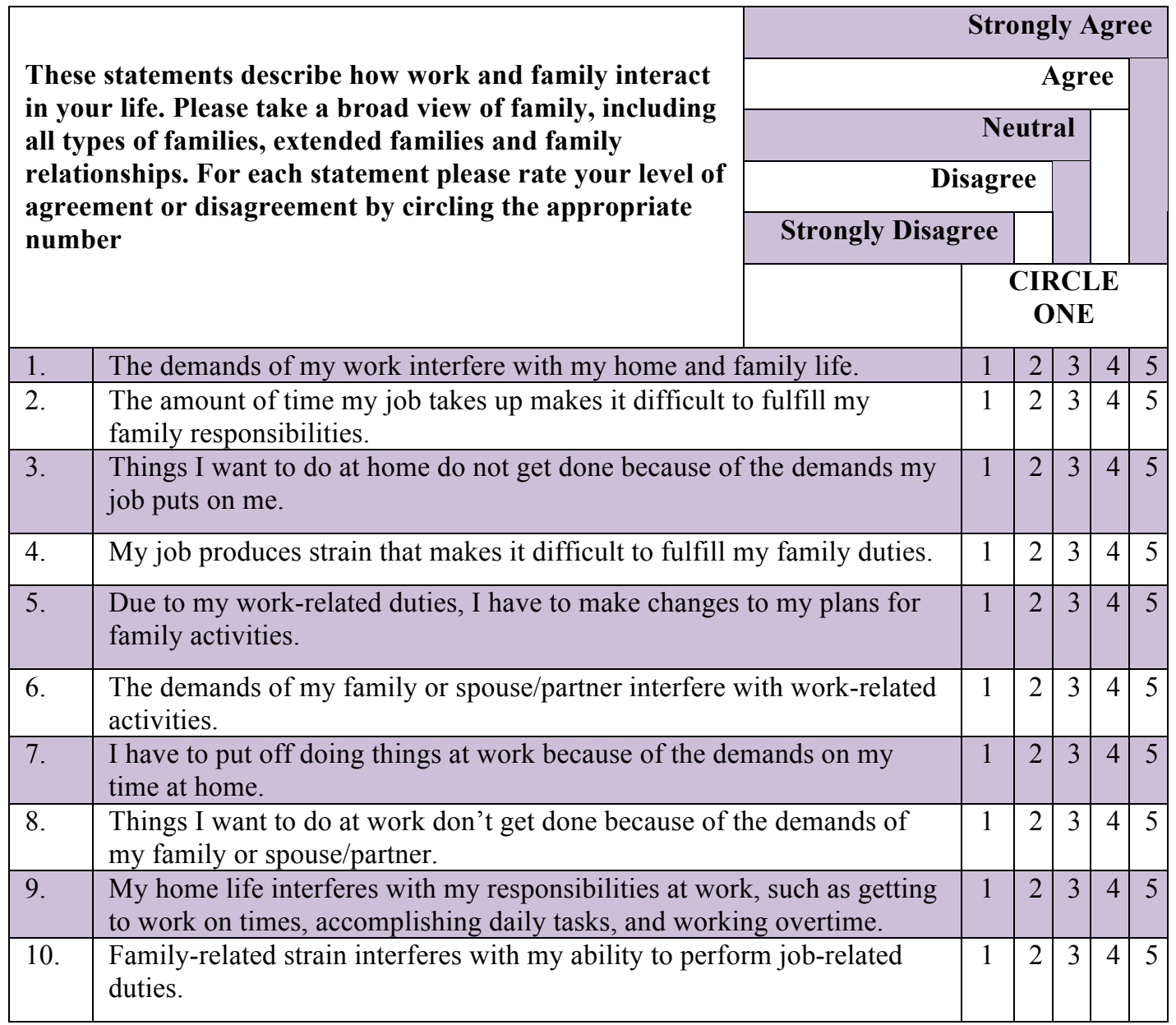




\section{Appendix C}

\section{Turnover Intentions}

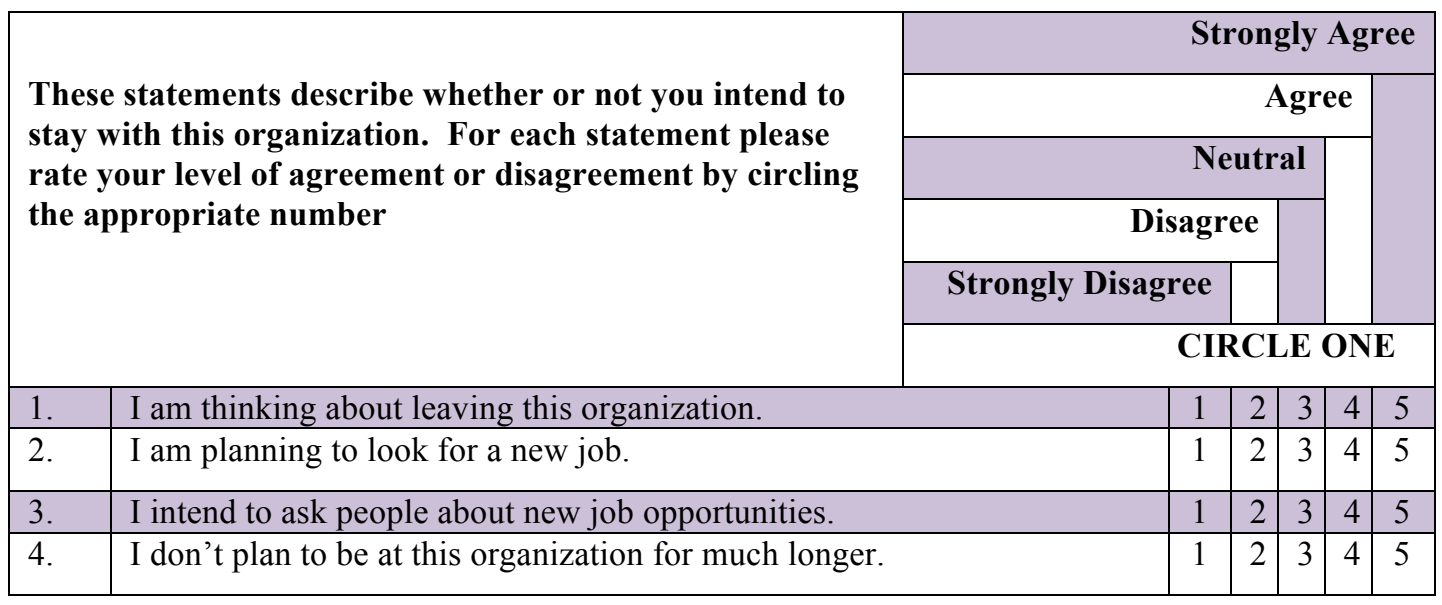




\section{Appendix D}

\section{Perceived Coworker Social Support}

\begin{tabular}{|c|c|c|c|c|c|c|c|}
\hline \multirow{4}{*}{\multicolumn{2}{|c|}{$\begin{array}{l}\text { These statements describe how much social support from } \\
\text { co-workers you feel in the workplace. For each statement } \\
\text { please rate your level of agreement or disagreement by } \\
\text { circling the appropriate number }\end{array}$}} & & \multicolumn{5}{|c|}{ All of the time } \\
\hline & & \multicolumn{6}{|c|}{ Most of the time } \\
\hline & & \multicolumn{5}{|c|}{ Some of the time } & \\
\hline & & \multicolumn{4}{|c|}{ Rarely } & & \\
\hline & & \multicolumn{3}{|c|}{ Never } & & & \\
\hline & & & \multicolumn{5}{|c|}{ CIRLCE ONE } \\
\hline 1. & \multicolumn{2}{|l|}{ My co-workers go out of their way to make my life easier. } & 1 & 2 & 3 & 4 & 5 \\
\hline 2. & \multicolumn{2}{|l|}{ It is easy to talk with my co-workers. } & 1 & 2 & 3 & 4 & 5 \\
\hline 3. & \multicolumn{2}{|c|}{ My co-workers can be relied upon when things get tough for me at work. } & 1 & 2 & 3 & 4 & 5 \\
\hline 4. & \multicolumn{2}{|c|}{ My co-workers are willing to listen to my personal problems. } & 1 & 2 & 3 & 4 & 5 \\
\hline 5. & \multicolumn{2}{|l|}{ My co-workers respect me. } & 1 & 2 & 3 & 4 & 5 \\
\hline 6. & \multicolumn{2}{|l|}{ My co-workers appreciate the work I do. } & 1 & 2 & 3 & 4 & 5 \\
\hline
\end{tabular}




\section{Appendix E}

\section{Positive and Negative Affect Schedule - Short Form (PANAS - SF)}

\begin{tabular}{|c|c|c|c|c|c|c|}
\hline \multirow{4}{*}{\multicolumn{2}{|c|}{$\begin{array}{l}\text { For each statement please rate the frequency with which } \\
\text { you experience the following by CIRCLING the } \\
\text { appropriate number. Thinking about yourself and how } \\
\text { you normally feel, to what extent do you generally feel: }\end{array}$}} & \multicolumn{5}{|c|}{ All of the time } \\
\hline & & \multicolumn{4}{|c|}{ Most of the time } & \\
\hline & & \multicolumn{4}{|c|}{ Some of the time } & \\
\hline & & \multicolumn{2}{|c|}{ Rarely } & & & \\
\hline & & \multicolumn{2}{|c|}{ Never } & & & \\
\hline & & \multicolumn{5}{|c|}{ CIRCLE ONE } \\
\hline 1. & Upset & 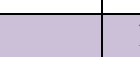 & 2 & 3 & 4 & 5 \\
\hline 2. & Hostile & 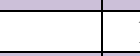 & 2 & 3 & 4 & 5 \\
\hline 3. & Alert & 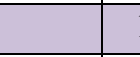 & 2 & 3 & 4 & 5 \\
\hline 4. & Ashamed & 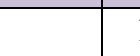 & 2 & 3 & 4 & 5 \\
\hline 5. & Inspired & 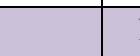 & 2 & 3 & 4 & 5 \\
\hline 6. & Nervous & 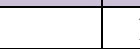 & 2 & 3 & 4 & 5 \\
\hline 7. & Determined & 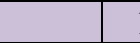 & 2 & 3 & 4 & 5 \\
\hline 8. & Attentive & 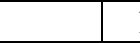 & 2 & 3 & 4 & 5 \\
\hline 9. & Afraid & 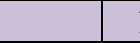 & 2 & 3 & 4 & 5 \\
\hline 10. & Active & 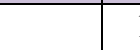 & 2 & 3 & 4 & 5 \\
\hline
\end{tabular}




\section{Appendix F \\ Demographic Questionnaire}

\begin{tabular}{|c|c|}
\hline \multicolumn{2}{|c|}{$\begin{array}{l}\text { Background Information (Please write answer in space provided) This information is necessary } \\
\text { for our study. }\end{array}$} \\
\hline What is your age? & \\
\hline 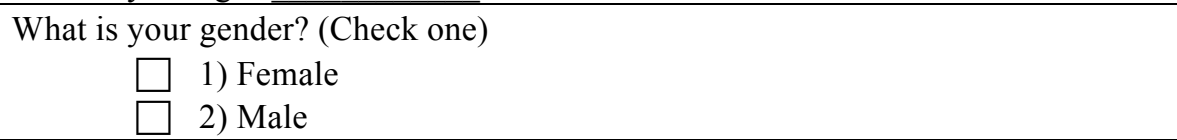 & \\
\hline $\begin{array}{l}\text { How would you describe your race? (Check all that apply) } \\
\text { [ ] White } \\
\text { [ ] Black or African American } \\
\text { [ ] American Indian or Alaskan native } \\
\text { [ ] Asian } \\
\text { [ ] Native Hawaiian or other Pacific Islander } \\
\text { [ ] Other [ ] }\end{array}$ & \\
\hline 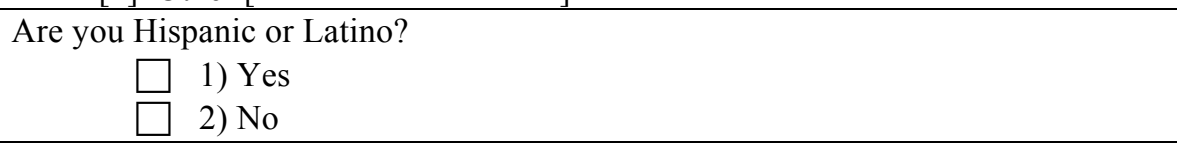 & \\
\hline 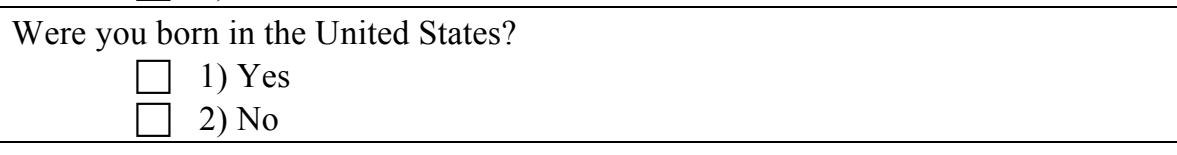 & \\
\hline $\begin{array}{l}\text { What is the highest level of education you have completed? (Check one) } \\
\qquad \begin{array}{l}\square \text { 1) Some high school } \\
\square \text { 2) High school diploma or GED } \\
\square \text { 3) Some college or associate's degree } \\
\square \text { 4) Bachelor's degree } \\
\square \text { 5) Graduate degree }\end{array}\end{array}$ & \\
\hline $\begin{array}{l}\text { How long have you worked in your current job? } \\
\text { Years }\end{array}$ & \\
\hline How many hours do you currently work per week? _ In hours & \\
\hline $\begin{array}{l}\text { Which of the following best describes your work schedule at this job? } \\
\square \text { 1) Variable schedule (one that changes from day to day) } \\
\square \text { 2) Regular daytime schedule } \\
\square \text { 3) Regular evening shift } \\
\square \text { 4) Regular night shift } \\
\square \text { 5) Rotating shift (one that changes regularly from days to evenings or } \\
\text { nights) } \\
\square \text { 6) Split shift (one consisting of two distinct periods each day) } \\
\square \text { 7) Other (specify) }\end{array}$ & \\
\hline $\begin{array}{l}\text { What is your relationship status? (Check one) } \\
\qquad \begin{array}{l}\square \text { 1) Married or partnered } \\
\square \text { 2) Divorced or separated } \\
\square \text { 3) Widowed } \\
\square \text { 4) Living with significant other } \\
\square \text { 5) Never married }\end{array}\end{array}$ & \\
\hline
\end{tabular}


You and Your Family (Please read each statement and fill in the blank or check the box to indicate your response as it relates to how things really are for you.)

How many dependents do you care for under the age of 18 ?

During the past 6 months have you provided at least 3 hours of care per week to an adult relative inside or outside your home? This could include help with shopping, medical care, or assistance in financial/ budget planning.

$\square$ 1) Yes

2) No 